\title{
27
}

\section{Role and Regulation of Osmolytes and ABA Interaction in Salt and Drought Stress Tolerance}

Guddimalli Rajasheker ${ }^{1}$, Gandra Jawahar ${ }^{1}$, Naravula Jalaja ${ }^{2}$, Somanaboina Anil Kumar ${ }^{1}$, Palavalasa Hima Kumari ${ }^{1}$, Devineni Lakshmi Punita ${ }^{1}$, Appa Rao Karumanchi, Palakolanu Sudhakar Reddy, Polavarapu Rathnagiri, Nese Sreenivasulu ${ }^{6}$ and Polavarapu Bilhan Kavi Kishor ${ }^{1}$

${ }^{1}$ Department of Genetics, Osmania University, Hyderabad, Telangana, India ${ }^{2}$ Department of Biotechnology, Vignan University, Vadlamudi, Guntur, India ${ }^{3}$ Department of Biotechnology, Acharya Nagarjuna University, Nagarjuna Nagar, Guntur, India ${ }^{4}$ International Crops Research Institute for the Semi-Arid Tropics (ICRISAT), Patancheru, Hyderabad, Telangana, India ${ }^{5}$ Genomix CARL Pvt. Ltd., Kadapa, Andhra Pradesh, India ${ }^{6}$ Grain Quality and Nutrition Center, Plant Breeding Division, International Rice Research Institute, Metro Manila, Philippines

\section{O U T L I N E}

27.1 Introduction

27.2 Abscisic Acid-Sensing Mechanism of Plants and Downstream Events

27.3 Role of Abscisic Acid in Osmolyte Biosynthesis

27.3.1 Abscisic Acid-Dependent and -Independent Signaling Pathways and Proline Biosynthesis

27.3.2 Role of Hormones in the Regulation of P5CS and Proline Synthesis

27.4 Regulation of Proline Dehydrogenase 27.4.1 Glycine Betaine Biosynthesis and Its Modulation by Abscisic Acid

27.5 Signaling Molecules and Osmolyte Synthesis
41827.6 Functions of Osmolytes During Abiotic Stress 27.6.1 Osmolyte Accumulation and Osmotic Adjustment During Stress

27.6.2 Osmolytes and Protection of Photosynthetic Machinery During Abiotic Stress

27.6.3 Osmolyte Accumulation and Oxidative Stress

27.6.4 Osmolytes and Amelioration of $\mathrm{NaCl}$ - and Metal-Induced $\mathrm{K}^{+}$Efflux Under Stress 426

27.6.5 Osmolytes and Their Metal Chelation Properties During Metal Stress 426

27.6.6 Role of Osmolytes in Membrane and Native Protein Structure Stabilizations 428

27.6.7 Osmolytes as Sources of Energy and Carbon Reserve During and After the Release of Stress 
27.7 Osmolytes and Signaling Processes

27.7.1 Proline and Signaling Processes

27.7.2 Proline Metabolism and Signaling Pathways in Plant Senescence

27.7.3 Osmolytes as Sensing Compounds and/or Growth Regulators
429

429

429

430
27.8 Conclusions and Future Prospects

Acknowledgments

References

Further Reading

\subsection{INTRODUCTION}

Plants are constantly exposed to diverse abiotic stresses like salinity, drought, cold, high temperature, and high light intensity (photooxidative stress) during their life cycle. Such stresses initiate oxidative stress releasing reactive oxygen species (ROS) that comprise free radicals $\left(\mathrm{O}_{2}{ }^{\bullet},{ }^{1} \mathrm{O}_{2}, . \mathrm{OH}, \mathrm{HO}_{2}\right.$ • $)$ and nonradical forms $\left(\mathrm{H}_{2} \mathrm{O}_{2}\right)$. Production of ROS damages cellular fabric, disrupts metabolism, and causes functional loss of cell organelles. This leads to death of plants in the majority of the cases (Blokhina et al., 2003; Khan and Khan, 2017). To minimize the deleterious effect of ROS, plants develop mechanisms such as scavenging them with antioxidative enzyme systems like ascorbate peroxidase (APX), catalase (CAT), glutathione $S$-transferase, superoxide dismutase (SOD), etc., or quenching them with the help of nonenzymatic molecules such as ascorbic acid, reduced glutathione, $\alpha$-tocopherol, carotenoids, flavonoids, and osmolytes such proline, glycine betaine (GB), mannitol, and trehalose (Khan and Khan, 2014; Khan et al., 2014, 2015; Per et al., 2018). Several compatible solutes or osmolytes are synthesized in bacteria as well as in plant systems when exposed to abiotic stresses. They protect protein structure stability and also scavenge the ROS as mentioned. Biosynthesis of certain osmolytes like proline and signaling contribute to the redox balance of cells under abiotic stress as well devoid of stress as has been pointed out by Per et al. (2017). However, multiple pathways exist for osmolyte biosynthesis in bacteria as well as in plants and the gene regulation is complex. The synthesis and accumulation of osmolytes is certainly controlled by phytohormones besides many other factors like mineral nutrients (Per et al., 2017). By interacting synergistically with proline and GB metabolism, phytohormones bring about stress tolerance in plants (Iqbal et al., 2014). But, the comprehensive role of hormones in modulating many osmolyte biosynthesis leading to salt and drought stress tolerance is not totally explored. Further, several signaling molecules like nitric oxide (NO), carbon monoxide (CO), and hydrogen sulfide $\left(\mathrm{H}_{2} \mathrm{~S}\right)$ play a pivotal role in the regulation of osmolyte biosynthesis ( $\mathrm{He}$ and $\mathrm{He}, 2017$ ).
Accordingly, it is vital to understand the role of these molecules on osmolyte accumulation and metabolism to resolve the adaptive roles played by plants to avoid abiotic stresses. This review focuses on two such osmolyte molecules, proline and GB, which are well studied and modulated by ABA and other phytohormones and the associated signaling pathways. The regulation of other osmolytes by hormones is not well known, and hence not included here. Myriad functions that are performed by osmolytes during stress, plant growth, and development are also emphasized. This review may provide new insights and opportunities in modulating osmolyte metabolism to impart salt and drought stress tolerance to crop plants, thereby contributing to sustainable agricultural yields in future.

\subsection{ABSCISIC ACID-SENSING MECHANISM OF PLANTS AND DOWNSTREAM EVENTS}

Abscisic acid (ABA) plays an important role in seed development, dormancy, and acclimation of plants to abiotic stresses. When plants are exposed to salt or drought stresses, rapid de novo synthesis of ABA was observed in leaves. This leads to the closure of stomata, which helps in protecting the plants against evaporation of water (Schwartz and Zeevaart, 2010). Henson (1984) and Mohapatra et al. (1988) reported enhanced levels of ABA in tissues exposed to abiotic stresses. Further, ABA plays a pivotal role during drought stress by modulating many physiological responses that lead to plant adaptations to unfavorable conditions. Exogenous application of ABA can also induce several genes in plants that are not subjected to stress (Mundy and Chua, 1988). This indicates that $\mathrm{ABA}$ is associated with functions other than abiotic stress. ABA signaling pathway perceives and transmits the hormone stimulus to activate several of the downstream events in the plants (Fujii et al., 2009; Ma et al., 2009; Park et al., 2009). This comprises three protein classes, namely pyrabactin resistance (PYR)/pyrabactin resistance-like (PYL)/regulatory component of ABA receptor (RCAR), which regulate protein phosphatase 2C (PP2C) negatively (Fig. 27.1A), and the positive 
(A)

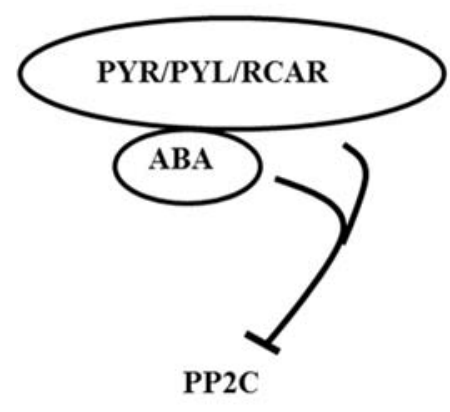

(B)

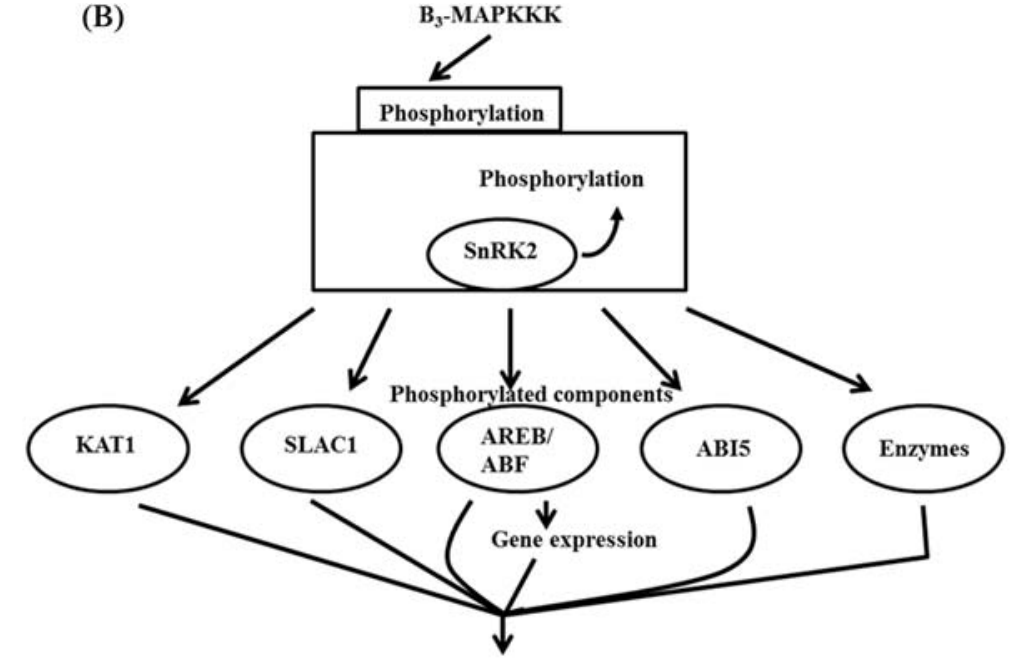

ABA-induced responses such as abiotic stress response, stomatal closure, seed maturation are observed

FIGURE 27.1 Abscisic acid signaling module. (A) An abscisic acid signaling module involves the presence of ABA, ABA receptors PYR/ PYL/RCAR which bind to ABA and inhibit protein phosphatase 2C (PP2C). (B) PP2C inhibition activates SnRK2s through autophosphorylation. SnRK2 then phosphorylates the downstream targets initiating abiotic stress responses.

regulators sucrose nonfermenting 1-related protein kinase type 2 (SnRK2s) (Fig. 27.1B). When enough concentrations of ABA are not present in the plant systems, SnRK2s are inactivated by PP2Cs (Umezawa et al., 2010). Once ABA binds to PYR/PYL/RCAR receptors, they undergo conformational change that allows the binding of PP2C (Cutler et al., 2010; Seiler et al., 2014). Therefore, ABA-induced inhibition of PP2Cs leads to phosphorylation of SnRK2 and its activation (Boudsocq et al., 2007). It has been found that SnRK2 activity is sensitive to staurosporine, but not to hyperosmolarity or ABA. This infers that SnRK2 activation by phosphorylation is mediated by staurosporine-insensitive kinase. SnRK2s then can phosphorylate downstream proteins like ion channels, NADPH oxidases, and others (Sah et al., 2016). While a Raf-like kinase (B-MAPKKK) activates SnRK2, a casein kinase 2 phosphorylates SnRK2's carboxyl-terminal serine residues. This enhances SnRK2PP2C interaction and thus, ABA can bring about activation of several of the downstream events.

\subsection{ROLE OF ABSCISIC ACID IN OSMOLYTE BIOSYNTHESIS}

\subsubsection{Abscisic Acid-Dependent and - Independent Signaling Pathways and Proline Biosynthesis}

Proline accumulation is a primary response to stress and is dependent on de novo synthesis (Verbruggen et al., 1993; Per et al., 2017). Therefore, the upstream signaling cascade must be in place for controlling proline biosynthesis as has been pointed out earlier (Hare et al., 1999). But, the signal transduction events controlling P5CS1 are not completely known. However, it has been shown that different signaling pathways regulate P5CS1 during cold and osmotic stress (Yoshiba et al., 1995; Igarashi et al., 2000; Hare et al., 1999). While AtP5CS1 is strongly ABAresponsive, AtP5CS2 is moderately responsive (Strizhov et al., 1997; Abrahám et al., 2003). Induction of AtP5CS transcript in salt-treated seedlings is associated with the early transcriptional response regulated by ABA signaling, but not observed by the deficiency of ABA biosynthesis in the abal Arabidopsis mutant (Strizhov et al., 1997). On the other hand, AtP5CS2 mRNA level is inhibited by cycloheximide. Mutations abi1 and axr2 affecting ABA-perception in Arabidopsis decrease the accumulation of both AtP5CS mRNAs during salt stress. At the same time, ABA signaling functions defined by the abi2 and abi3 mutations have no effect on salt induction of the P5CS genes (Strizhov et al., 1997). Verslues and Bray (2006) pointed out that low water potential-induced proline accumulation requires $A B A$ levels like those of wild-type levels. Estimations of ABA and proline levels in ABAinsensitive mutants, abi1-1, abi2-1, abi3, abi4, and abi5 revealed that abi4 had higher accumulation of proline at low water potential, but a reduced response to exogenous ABA. They found out that these responses could be modified by sucrose treatment. Also, while abi1 had reduced accumulation of proline in response to low water potential and ABA application, abi1-1 and abi2-1 had enhanced ABA accumulation. ABA-insensitive mutants are impaired in their response to sugars also 
(Gibson, 2005). It is known that sucrose inhibits ABAinduced proline accumulation (Verslues and Bray, 2006). It appears therefore, that ABI4 is connected to $\mathrm{ABA}$ and sugar-signaling in the regulation of proline accumulation (Verslues and Bray, 2006). Also, ABAdependent induction of P5CS1 expression is prevented by pretreatment with the hormone brassinosteroid (Abrahám et al., 2003). Thus, their analysis suggests the existence of both ABA-dependent and ABAindependent signaling pathways. Further, analysis of the P5CS1 and P5CS2 promoters showed the presence of cis-acting ABA-responsive elements only in P5CS1, but not P5CS2. Also, no dehydration-responsive element could be identified in the promoter sequences (Hare et al., 1999). In contrast, P5CS2 is weakly induced by ABA. It has been discovered that MYB-type of transcription factors PHOSPHATE STARVATION RESPONSE1 (PHR1) and PHR1-LIKE1 (PHL1) bind to P5CS1 regulatory sequences in the first intron, which contains a conserved PHR1-binding site motif (Aleksza et al., 2017). Phosphate starvation of Arabidopsis seedlings led to the activation of P5CS1, proline dehydrogenase 2 (ProDH2), as well as an increase in proline content. Such an accumulation was not noticed in the ABA-deficient aba1-3 and ABA-insensitive abi4-1 mutants. They also noticed that ABA is implicated in growth retardation in such nutritional stress. These results point out that proline biosynthesis is modulated by a crosstalk between ABA signaling and regulation of phosphate homeostasis through PHR1- and PHL1mediated transcriptional activation of the P5CS1 gene (Aleksza et al., 2017). Factors affecting P5CS and proline dehydrogenase (ProDH), enzymes associated in proline metabolism, are shown in the Table 27.1.

\subsubsection{Role of Hormones in the Regulation of P5CS and Proline Synthesis}

The results of You et al. (2012) indicated that ornithine $\delta$-aminotransferase $(O A T)$ is strongly induced by ABA and indole-3-acetic acid, and is slightly induced by brassinosteroids and jasmonic acid (JA) indicating that $O A T$ is responsive to multiple stresses. You et al. (2012) found out that the drought-induced expression of OsOAT is contributed by both ABA-dependent and ABA-independent pathways. Auxin upregulates the expression levels of both P5CS1 and P5CS2 genes, while cytokinin downregulates P5CS1, but enhances the expression of P5CS2 (Yoshiba et al., 1995; Strizhov et al., 1997; Hare et al., 1999; Abrahám et al., 2003). Induction of P5CS1 is light-dependent. Also, both ABA and salt stress strongly activate P5CS1 gene in Arabidopsis. At the same time, ABA and salt stress weakly stimulate P5CS2 gene and downregulate PDH gene expression in light-grown Arabidopsis plants
(Abrahám et al., 2003). Thus, their experiments proved that proline accumulation is strongly dependent on light, salt stress, and ABA, which is due to the activation of P5CS1 gene. At the same time, ABA and lightdependent activation of P5CS1 gene is inhibited in dark-grown plants. Proline accumulation in response to ABA and salt stress is mostly controlled by lightdependent activation of P5CS1 gene, but is inhibited by brassinosteroid signaling in Arabidopsis thaliana (Abrahám et al., 2003). In Arabidopsis, dark conditions downregulated P5CS2. Induction of P5CS1 is increased in the ABA-hypersensitive pleiotropic regulatory locus1 (prl1) and brassinosteroid-deficient deetiolated 2 (det2) mutants. On the other hand, both ABA and salt stress increased the P5CS2 gene induction only in det2 mutants. Thus, proline accumulation is certainly controlled by ABA as well as salt stress via P5CS1 gene. In the S6P5CS promoter region, a methyl jasmonate (MeJA)-responsive motif (TGACG-motif) was predicted, inferring that MeJA activates SbP5CS expression (Su et al., 2011). Salicylic acid (SA) positively regulated proline metabolism and helped in proline accumulation in several plants (Kanade, 2008; Misra and Saxena, 2009). SA induced proline accumulation might be due to increased P5CR activity and the stress protective effect of SA is perhaps controlled due to proline accumulation. SA treatment enhanced the accumulation of proline in barley shoots but not in roots (El-Tayeb, 2005). SA signaling is also associated with the expression of P5CS2 after infection with avirulent Pseudomonas (Fabro et al., 2004). Indeed, SAresponsive element was noticed in the promoter region of SbP5CS (Su et al., 2011). Likewise, a gibberellin (GA)-responsive element, GARE, was predicted in the upstream region of SbP5CS gene. But, no experiment was conducted to show that GA activates P5CS expression. Brassinosteroids inhibited the expression of both P5CS1 and P5CS2, and they could not stimulate ProDH expression (Abrahám et al., 2003). Thus, regulation of P5CS1 appears to be rather complex. During stress conditions, other secondary messengers or hormones like $\mathrm{NO}$ and ROS such as hydrogen peroxide $\left(\mathrm{H}_{2} \mathrm{O}_{2}\right)$ are known to mediate $\mathrm{ABA}$ signals and affect proline metabolism as has been shown by Desikan et al. (2002), Neill et al. (2008), and Yang et al. (2009). NO has been shown to be involved in the ABA-induced proline accumulation in wheat seedlings (Hai-Hua et al., 2004). While NO treatment enhanced the copperinduced proline accumulation (Zhang et al., 2008), the same was not noticed in Brassica rapa under salt stress conditions (Lopez-Carrion et al., 2008). It increased the activity of P5CS1, but downregulated the activity of ProDH in wheat (Hai-Hua et al., 2004). NO stimulated P5CS1 expression in Arabidopsis, but inhibited the expression of ProDH1 (Zhao et al., 2009). They also noticed that nitrate reductase rather than NO synthase 
TABLE 27.1 Factors Affecting P5CS1, ProDH, and Proline Accumulation in Plants

\begin{tabular}{|c|c|c|}
\hline Factor & Gene/expression & References \\
\hline Phosphate starvation & ProDH2 upregulation in A. thaliana & Aleksza et al. (2017) \\
\hline Light & P5CS1 upregulation in A. thaliana & Feng et al. (2016) \\
\hline Heat/temperature & P5CS1 upregulation in A. thaliana and Prunus persica & Shin et al. (2016), Wei-Tao et al. (2011) \\
\hline Hydrogen peroxide & P5CS1 upregulation in A. thaliana & Ben Rejeb et al. (2015) \\
\hline Diphenylene iodonium & P5CS1 downregulation in A. thaliana & Ben Rejeb et al. (2015) \\
\hline Menadione sodium bisulfite & P5CS1 upregulation in A. thaliana & Jiménez-Arias et al. (2015) \\
\hline Salt stress & ProT upregulation in Kosteletzkya virginica & Wang et al. (2015) \\
\hline Salt stress & OAT upregulation in Kosteletzkya virginica & Wang et al. (2015) \\
\hline Phosphatidylinositol 3-kinase & ProDH1 upregulation in A. thaliana & Leprince et al. (2015) \\
\hline $\mathrm{H} 2 \mathrm{~S}$ & Downregulation of ProDH1 in Musa paradisica & Luo et al. (2015) \\
\hline Salt stress & ProDH1 downregulation Saccharomyces cerevisiae and Helianthus tuberosus & Huang et al. (2013) \\
\hline Methyl jasmonate & P5CS2 upregulation in Sorghum bicolor & Su et al. (2011) \\
\hline Nitric oxide & P5CS1 upregulation in A. thaliana & Zhao et al. (2009) \\
\hline Carbon monoxide (CO) & P5CS1 upregulation in Triticum aestivum & Yuan et al. (2009) \\
\hline Phospholipase C & P5CS1 upregulation in A. thaliana & Parre et al. (2007) \\
\hline Phospholipase D & P5CS1 downregulation under nonstress conditions in A. thaliana & Thiery et al. (2004) \\
\hline Salicylic acid & P5CS2 upregulation in A. thaliana & Fabro et al. (2004) \\
\hline Pathogens & P5CS2 upregulation in A. thaliana & Fabro et al. (2004) \\
\hline Rehydration & ProDH1 upregulation in A. thaliana & Satoh et al. (2002) \\
\hline Brassinosteroids & P5CS2 downregulation in A. thaliana & Abrahám et al. (2003) \\
\hline Metal & P5CS1 upregulation/overexpression in Chlamydomonas reinhardtii & Siripornadulsil et al. (2002) \\
\hline Light & P5CS1 upregulation in A. thaliana & Hayashi et al. (2000) \\
\hline Dark conditions & ProDH1 upregulation in A. thaliana & Hayashi et al. (2000) \\
\hline Cold/Low temperature & P5CS1 upregulation in Oryza sativa & Igarashi et al. (1997) \\
\hline Abscisic acid & P5CS1 upregulation in A. thaliana & Strizhov et al. (1997) \\
\hline Indole-3-acetic acid & P5CS1 upregulation in A. thaliana & Strizhov et al. (1997) \\
\hline Salt stress & ProDH1 downregulation Saccharomyces cerevisiae and Helianthus tuberosus & Peng et al. (1996) \\
\hline Water stress & ProDH1 downregulation in A. thaliana & Kiyosue et al. (1996) \\
\hline Salt stress & P5CS1 upregulation in A. thaliana & Yoshiba et al. (1995) \\
\hline Drought & P5CS1 upregulation in A. thaliana & Savouré et al. (1995) \\
\hline Low nitrogen & P5CS1 upregulation in Vigna aconitifolia & Delauney et al. (1993) \\
\hline
\end{tabular}

is responsible for NO-mediated regulation of proline accumulation and also freezing tolerance.

Experiments to unravel the upstream signaling pathway of P5CS gene resulted in the identification of phospholipase $\mathrm{D}$, involved in water stress response and ABA signal transduction (Hallouin et al., 2002). But, phospholipase D downregulated P5CS1 activity under normal and also abiotic stress conditions (Thiery et al., 2004). It is known that calcium plays a pivotal role in proline accumulation under salt stress conditions. But, $\mathrm{CaCl}_{2}$ and phospholipase $\mathrm{D}$ treatment resulted in the upregulation of P5CS1 gene. They suggested that calcium regulates phospholipase $\mathrm{D}$ as a downstream signal messenger. However, there are many gaps in our understanding of the activation of some of the enzymes involved in proline metabolism 
and signaling pathways. Also, how some of these hormones regulatedP5CS and ProDH expressions at the molecular level and controlled the fine tuning of proline accumulation or degradation during stress, plant growth, and development is still to be discovered and perhaps pivotal for a comprehensive understanding of this osmolyte. Nevertheless, these experiments revealed a link between proline, hormonal signal, and downstream stress responses in plants.

\subsection{REGULATION OF PROLINE DEHYDROGENASE}

Dark conditions upregulated ProDH gene in shoots. ProDH was inhibited by both ABA and salt stress in shoots and roots of light-grown plants unlike that of P5CS1. In Arabidopsis, while prl1 mutation reduced the basal level of $P D H$ gene expression, the det2 mutation enhanced the inhibition of $P D H$ by ABA (Abrahám et al., 2003). Thus, it appears that $P D H$ expression is also regulated by $\mathrm{ABA}$. In plants, the receptors histidine kinases (AHKs) and elements of the twocomponent system have been proposed to function in water stress responses by regulating various stress-responsive genes. But, not much information is available concerning AHK phosphorelay-mediated downstream signaling (Veerabagu et al., 2014). ProDH is associated with the catabolic process and converts proline to pyrroline-5-carboxylate (P5C). It is known that ProDH1 expression undergoes extensive regulation by exogenous and endogenous signals, but the mechanism of its transcriptional and posttranscriptional regulation is not known completely. Accumulation of ProDH1 is controlled by the ACTCAT cis-acting element (ACT-box) in the ProDH1 promoter (Satoh et al., 2002) via basic region leucine zipper (bZIP) transcriptional activators from the S1group (Satoh et al., 2004). Analysis of ProDH1 regulation revealed that the S1-group members of TFs like bZIP1 and bZIP53 bind to the promoter of ProDH (Dietrich et al., 2011). But, not much is known about the functioning of C-group bZIP factors except perhaps AtbZIP63, which is a sensitive integrator of transient ABA and glucose signals under water stress (Matiolli et al., 2011). Veerabagu et al. (2014) have shown that the Arabidopsis type-B response regulator 18 (ARR18) acts as an osmotic stress response regulator in the seeds of Arabidopsis. This regulator affects the activity of the ProDH1 promoter, controlled by C-group bZIP transcription factors. They showed that ARR18 interaction negatively interferes with the bZIP63 on the ProDH1 promoter. Thus, regulation of ProDH via response regulators appears to be crucial for osmotic stress tolerance. However, such response regulators have not yet been discovered for other genes involved in the biosynthesis of other osmolytes.

\subsubsection{Glycine Betaine Biosynthesis and Its Modulation by Abscisic Acid}

GB interacts with plant hormones including ABA. Drought stress induced ABA accumulation was noticed first in corn, followed by GB accumulation (Zhang et al., 2012a,b). Thus, ABA and GB are positively associated with stress tolerance in plants. Both in wheat and pears, water stress has increased GB accumulation (Nayyar and Walia, 2004; Gao et al., 2004b). Zhang et al. (2012a,b) noticed enhanced GB accumulation with the application of ABA and also leaf relative water content and shoot dry matter production in two maize cultivars during water stress. They concluded that endogenous $\mathrm{ABA}$ is involved in modulating GB accumulation. Kurepin et al. (2015) reported upregulation of the genes associated with the GB biosynthetic pathway by increases in ABA and SA contents. An interplay between these hormones and GB appeared necessary for protection of photosynthesis under abiotic stress conditions. Synergistic effects of $\mathrm{ABA}$ and GB have been shown to protect photosynthetic apparatus in the cold acclimation process in higher plants (Kurepin et al., 2015). Transgenic plants overexpressing GB biosynthetic pathway genes produced better biomass in comparison with untransformed plants under stress (Hayashi et al., 1998). But, many researchers (Kurepin et al., 2013; Hüner et al., 2014) are of the opinion that GB in nonstressed plants can modify the production of endogenous phytohormones (ABA, ethylene, SA) associated with plant stress responses. It is not only drought stress conditions that increased the betaine aldehyde dehydrogenase (BADH) mRNA levels, even exogenously supplied ABA upregulated the BADH mRNA in leaves and roots of barley (Ishitani et al., 1995; Jagendorf and Takabe, 2001). Besides ABA and SA, JA also enhanced the GB accumulation in higher plants (Jagendorf and Takabe, 2001; Gao et al., 2004a). This implied that GB biosynthesis is under the hormonal control like that of proline. Taken together, it is suggested that a close interaction and synergistic effect of $A B A$ and $G B$ are necessary for effective acclimation of freezing and abiotic stress tolerance in plants. The above results also indicated that the hormone ABA transduces the signal for the biosynthesis of GB. But, how the signal is transduced and what are the different components associated in the pathway are not known. While proline biosynthesis is mediated by both ABA-dependent and ABA-independent signaling pathways (Hare et al., 1999), in contrast, GB biosynthesis appeared upregulated directly by ABA. 
But, not much is known about the regulation of the genes associated with the biosynthesis of other osmolytes like proline derivatives, GB derivatives, trehalose, and sugar alcohols by ABA and other hormones.

\subsection{SIGNALING MOLECULES AND OSMOLYTE SYNTHESIS}

Environmental stresses result in the production of signaling molecules like $\mathrm{NO}, \mathrm{CO}$, and $\mathrm{H}_{2} \mathrm{~S}$ in plants (He and He, 2017). However, the molecular mechanisms associated with the induction of osmolyte synthesis are not totally known. Evidence exists that NO induces one of the important osmolytes, proline, in wheat (Hai-Hua et al., 2004), Chinese cabbage (LopezCarrion et al., 2008), and rye grass (Liu et al., 2010) by upregulating P5CS and downregulating ProDH genes. Ke et al. (2014) reported that NO is associated with salt tolerance by regulating proline metabolism in tobacco, thus indicating the importance of $\mathrm{NO}$ in proline synthesis during abiotic stress. Yuan et al. (2009), Zhang et al. $(2012 a, b)$ reported CO stimulated P5CS and suppression of ProDH in wheat and Cassia obtusifolia seedlings as well as salt stress alleviation. Luo et al. (2015) and Chen et al. (2016) reported chilling injury and drought stress alleviation respectively with $\mathrm{H}_{2} \mathrm{~S}$ treatment. Further, Tian et al. (2016) reported $\mathrm{H}_{2} \mathrm{~S}$ and proline ameliorated metal $(\mathrm{Cd})$ stress in foxtail millet inferring a complex regulatory mechanism for proline synthesis and its relation to abiotic stress alleviation. However, the molecular mechanisms underlying activation of the biosynthetic pathway genes of proline metabolism and also the effects of these signal molecules on the biosynthesis of other osmolytes have not been understood so far.

\subsection{FUNCTIONS OF OSMOLYTES DURING ABIOTIC STRESS}

\subsubsection{Osmolyte Accumulation and Osmotic Adjustment During Stress}

Compatible solute accumulation, known for its osmotic adjustment, has long been recognized (Brown and Simpson, 1972; Borowitzka and Brown, 1974). Further, a correlation has also been found between the quantity of compatible solute and stress tolerance levels in plants (Storey and Jones, 1977; Flowers and Hall, 1978; Kishor et al., 1995). Amino acids play a vital role in protein biosynthesis. However, certain amino acids like proline accumulate under stressful environment and impart stress tolerance by maintaining cell turgor or osmotic balance, stabilizing membranes thereby preventing electrolyte leakage (Szabados and Savoure, 2010). When proline and GB were supplied exogenously, plants displayed salt stress tolerance. Both of them mediate upregulation of genes associated with antioxidant defense and glyoxalase systems and thus protect seedlings of rice from salt-induced oxidative damage (Hasanuzzaman et al., 2014). A large number of plants were genetically modified with the biosynthetic pathway genes associated with proline (reviewed in Kumar et al., 2014) and GB (reviewed in Khan et al., 2009), which displayed higher tolerance to salt stress. Higher accumulation of proline and GB in leaves of transgenic lines has been noticed in comparison with untransformed plants. This indicated that introduced genes are properly integrated and expressed in the host genome. It appeared that accumulation in leaves of stressed plants is regulated, at least in part, via the changes in the expression of biosynthetic pathway genes. But, the signals that provoke these changes in gene expressions have not been clearly identified in higher plants. It is not clear how osmolytes like proline and GB affect the cell turgor in plants and what signals are associated with them. It seems that in yeast, Synthetic Lethal of $N$-end rule $1(S \ln 1)$ osmosensor histidine kinase monitors the changes in turgor pressure as demonstrated by Saito and Tatebayashi (2004). It has been shown that reduction in turgor pressure caused by hyperosmotic stress activates the mitogen activated protein kinase high osmolarity glycerol 1 (HOG1) through SLN1 branch of the glycerol pathway (Reiser et al., 2003). In higher plants, activity of the plant histidine kinase Cre1 (cytokinin response 1) is regulated by changes in turgor pressure like that of $\operatorname{Sln} 1$ in yeast. It is known that Cre1 complemented the deficient Hog1 response in $\operatorname{Sln} 1$ mutant yeast cells (Reiser et al., 2003). These authors proposed that Cre1 has dual functions in plants acting both as a cytokinin receptor and also as an osmosensor. In addition to the possible role of osmolytes in osmotic adjustment and in stabilizing membranes upon salt/water stress, they play several other important regulatory functions in stressed plants (Lokhande and Suprasanna, 2012). Sugars not only sustained the growth of sink tissues, but also affected sugar-sensing systems that regulated the expression, either positively or negatively, of a variety of genes involved in photosynthesis, respiration, and the synthesis and degradation of starch and sucrose (Hare et al., 1998). Accumulation of sugar alcohols such as mannitol, sorbitol, pinitol, and others might serve dual functions: facilitating osmotic adjustment and supporting redox control (Tarczynski et al., 1993; Shen et al., 1999). Similarly, other osmolytes exhibited multiple functions in plants (Bohnert and Shen, 1998; Shen et al., 1999; Elbein et al., 2003; Livingston et al., 2009). 


\subsubsection{Osmolytes and Protection of Photosynthetic Machinery During Abiotic Stress}

Light including ultraviolet light-B (UV-B) radiation stress affects plant productivity drastically by inhibiting photosynthetic activity. Therefore, plants accumulate proline besides several other antioxidative and flavonoid molecules (Saradhi et al., 1995). As shown by Arora and Saradhi (2002), proline might protect the plants by scavenging the singlet oxygen or free radicals generated during light or UV-B radiation stress. A combination of $\mathrm{NaCl}$ and UV-B radiation showed an additive effect on most of the parameters studied in barley. UV-B treatment decreased the chlorophyll/ carotenoid ratio in barley seedlings and also photochemical efficiency of PSII (Fedina et al., 2003). Fedina et al. (2003) pointed out that $\mathrm{NaCl}$ preexposure decreased $\mathrm{H}_{2} \mathrm{O}_{2}$ generation and alleviated the inhibitory effect of UV-B on PSII. Proline accumulated during $\mathrm{NaCl}$ preexposure might be one of the reasons for the observed tolerance of barley seedlings to UV-B radiation. Pretreatment of Senedesmus (algal member) with proline decreased lipid peroxidation and UV-B induced malondialdehyde (MDA) generation (Tripathi and Gaur, 2004). Thus far, the exact mechanism of light-dependent stimulation of proline biosynthetic pathway genes and proline accumulation are not known. It was shown by Uchida et al. (2002) that $\mathrm{H}_{2} \mathrm{O}_{2}$ pretreatment induces increased ROS scavenging enzyme activities and enhanced expression of P5CS, sucrose phosphate synthase, and the small heat shock protein 26 in rice. These experiments indicated that $\mathrm{NO}$ and $\mathrm{H}_{2} \mathrm{O}_{2}$ act as signaling molecules that modulate both salt and heat stress tolerance by regulating the gene expression associated with it. Likewise, transgenic Arabidopsis leaves that expressed choline oxidase (COD) gene for the accumulation of GB displayed enhanced levels of $\mathrm{H}_{2} \mathrm{O}_{2}$ in comparison with untransformed plants (Alia et al., 1999). Further, activities of the enzymes such as APX and CAT were higher in transgenics than in the wild-type plants. These results indicated that the $\mathrm{H}_{2} \mathrm{O}_{2}$ generated by overexpression of $C O D$ gene might have stimulated the expression of scavenging enzymes (Sakamoto and Murata, 2002). Thus, $\mathrm{H}_{2} \mathrm{O}_{2}$ generated during stress might play as a signal transducer in stimulating proline biosynthetic pathway gene P5CS as well as ROS scavenging enzymes under the influence of $C O D$.

Photosynthesis is a major target of high-temperature as well as other abiotic stresses in plants and PSII is the most temperature-sensitive component. It is known that GB enhances the tolerance of photosynthetic machinery to photoinhibition (Sakamoto and Murata, 2002). Gorham (1995) indicated that GB protects enzymes and protein complexes against heat-induced inactivation. Photoinhibition involves photoinduced damage to PSII and the light-dependent repair of PSII complex (Aro et al., 1993). Abiotic stresses especially high temperature impair the activity of Rubisco enzyme also in several species (Haldimann and Feller, 2005). While D1 protein, one of the constituents of PSII, is damaged, steps are taken immediately by the plant to ensure the removal and replacement of the damaged D1 protein. GB plays a dual function of repairing the PSII complex during photoinhibition as well as protecting the complex proteins (Allakhverdiev et al., 2007). Alia et al. (1998) reported protection of transgenic Arabidopsis lines overexpressing GB biosynthetic pathway genes. This could be because of the protection of Rubisco activase by GB, which was later supported by Yang et al. (2005) in transgenic tobacco. Alia et al. (1999) found out that $\operatorname{cod} A$ overexpression in Arabidopsis resulted in light stress tolerance. They also found that GB had no effect on photodamage, but participated in repair of the PSII complex. Holmström et al. (2000) revealed that overexpression of choline dehydrogenase $(\mathrm{CDH})$ in tobacco resulted in the removal of photodamaged D1 protein and reconstitution of the functional PSII complex. It is believed that increased $\mathrm{CO}_{2}$ assimilation rate in transgenic lines is associated with the Rubisco activase-mediated activation of Rubisco by GB (Yang et al., 2005). Proline has been found to reduce the inhibitory effects of $\mathrm{NaCl}$ on the activity of enzymes like Rubisco in vitro in Tamarix jordanis (Solomon et al., 1994). Papageorgiou and Murata (1995) showed that osmolytes prevented dissociation of the oxygen-evolving complex of photosystems II. Yang et al. (2005) also reported improved thermostability of the oxygen-evolving complex and the reaction center of PSII (Yang et al., 2007) when GB biosynthetic pathway genes are overexpressed. However, the mechanistic explanation of how exactly osmolytes, including GB, protect PSII under stress is not clear to date.

\subsubsection{Osmolyte Accumulation and Oxidative Stress}

Chloroplasts and mitochondria are the two powerhouses of plant systems. The redox state of these two cell organelles is maintained by a delicate balance between energy production and consumption. These organelles need to avoid always the excess production of ROS, especially under abiotic stress conditions. While optimal levels of ROS are useful for signal transduction and several developmental activities, excess amounts cause damage to the nucleic acids, oxidation of proteins and lipids, and degradation of chlorophyll molecules (Davies, 1987; Imlay and Linn, 1988). Plants need to utilize the redox cues that are generated both in chloroplasts and mitochondria not only for maintaining metabolic fluxes, but also for coping with 
environmental changes via a complex network (Suzuki et al., 2012). The degradation pathway of proline is downregulated during osmotic stress, allowing free proline to accumulate. Miller et al. (2009) showed that overexpression of MsProDH in tobacco and Arabidopsis or impairment of $\mathrm{P} 5 \mathrm{C}$ oxidation in the Arabidopsis $p 5 c d h$ mutant did not change the cellular proline to $\mathrm{P} 5 \mathrm{C}$ ratio under ambient and osmotic stress conditions. This reveals that excess $\mathrm{P} 5 \mathrm{C}$ is reduced to proline in a mitochondrial-cytosolic cycle. This cycle involves conversion of proline by ProDH to P5C and back to proline by P5CR enzyme and is known to exist in animal cells (P5C-proline cycle). Miller et al. (2009) demonstrated that when an excess of exogenous L-proline is provided, it generates mitochondrial ROS by delivering electrons to $\mathrm{O}_{2}$. This was demonstrated by them using mitochondria specific MitoSox staining of superoxide ions. When there is a lack of P5CDH enzyme activity, it has led to higher ROS production in the presence of excess proline (Miller et al., 2009). It appears therefore, balancing not only chloroplastic but also mitochondrial ROS production during enhanced proline oxidation is critical for avoiding proline related toxic effects. To avoid the generation of ROS production by P5C-proline cycling, plants must oxidize P5C back to glutamate by $\mathrm{P} 5 \mathrm{CDH}$.

Regulation of ROS is coordinated by both enzymatic and nonenzymatic mechanisms. Further, exogenous application of proline or genetic manipulation of its synthesis or degradation has amply demonstrated its role in plant responses to abiotic stresses in different species like tobacco, sugarcane, grapevine, and sorghum (Smirnoff and Cumbes, 1989; Okuma et al., 2004; Molinari et al., 2007; Ozden et al., 2009; Reddy et al., 2015). Proline has enhanced the primary photochemical activities in isolated thylakoid membranes of Brassica juncea by arresting photoinhibitory damage (Alia and Saradhi, 1991). They suggested that proline protects the components involved in water oxidation capacity by reducing the production of free radicals and/or scavenging the free radicals thereby reducing thylakoid lipid peroxidation. Alia et al. (1997) also proposed that proline produced a considerable reduction in the lipid peroxidation-linked formation of both conjugated dienes and MDA in the thylakoids during exposure to strong light. They demonstrated that proline is involved in reducing the photodamage in the thylakoid membranes by scavenging and/or reducing the production of singlet oxygen. Alia et al. (2001) utilized spin trapping electron paramagnetic resonance (EPR) spectroscopy for analyzing the singlet quenching action of proline. Their results show that proline is very effective in reducing the production of singlet oxygen $\left({ }^{1} \mathrm{O}_{2}\right)$. Quenching of ${ }^{1} \mathrm{O}_{2}$ by proline seems to be based on its capability to form a charge-transfer complex due to low ionization potential. Proline is also a scavenger of hydroxyl radicals $(\mathrm{OH})$ as shown by Smirnoff and Cumbes (1989). But, proline does not interact with superoxide radicals. Kaul et al. (2008) showed the free radical scavenging potential of Lproline using in vitro assay system. However, it is difficult to explain the exact mechanism of quenching of ${ }^{1} \mathrm{O}_{2}$ or $\mathrm{OH}$ by proline. Overall, it appears that proline can stabilize proteins, DNA, as well as membranes under stress conditions as has also been pointed out by Matysik et al. (2002). High proline producing genotypes of niger (Guizotia abyssinica) exhibited higher antioxidative enzymes compared with low proline producing lines (Sarvesh et al., 1996). Exogenous supply of proline alleviated the oxidative stress and increased the vase life of Rosa hybrida flowers (Kumar et al., 2010). This increase in vase life coincided with higher levels of endogenous proline, lower levels of superoxide radicals, and higher activity of $\mathrm{PDH}$ in proline treated flowers. Exogenous application of proline has also been shown to associate with antioxidative enzyme activities (Hoque et al., 2007a,b). Proline ameliorated the enzymatic inactivation of APX and peroxidase, while SOD and CAT activities were reduced in grapevine (Ozden et al., 2009). In transgenic sugarcane overexpressing P5CS, a negative correlation between proline and lipid peroxidation were observed. This suggested that proline might protect against osmotic stress by increasing antioxidant systems. De Campos et al. (2011) demonstrated that transgenic citrumelo plants were able to cope with water deficit better than untransformed controls. Since these transgenics expressing VignaP5CSF129A are able produce high endogenous proline levels, proline must have contributed to gas exchange parameters and elevated levels of antioxidative enzymes (APX, SOD) but not CAT, and thereby ameliorated the deleterious effects of drought-induced oxidative stress. Transgenic Sorghum bicolor plants overexpressing P5CSF129A also displayed higher proline and higher antioxidative enzyme activities under salt stress (Reddy et al., 2015). Kaushal et al. (2011) demonstrated that proline has induced heat tolerance in Cicer arietinum plants by protecting vital enzymes of carbon and antioxidative metabolism. Posmyk and Janas (2007) noticed a positive correlation between endogenous levels of proline content in seeds of Vigna radiata and germination upon exposure to chilling stress. When seeds of $V$. radiata were pretreated with proline, it had a stimulatory effect on germination. This increase in seed germination by exogenously supplied proline under chilling temperatures is attributed to its potential to stabilize cell membrane by quenching both ${ }^{1} \mathrm{O}_{2}$ and $\mathrm{OH}$. Heat stress induced $\mathrm{H}_{2} \mathrm{O}_{2}$ in Saccharum species, but pretreatment with proline and GB has substantially reduced the $\mathrm{H}_{2} \mathrm{O}_{2}$ production, improved the accumulation of soluble sugars, and protected the developing tissues from heat stress effects in sprouting sugarcane buds (Rasheed 
et al., 2011). Ben Rejeb et al. (2015) investigated the role of NADPH oxidases, respiratory burst oxidase homologues (Rboh) in the induction of proline accumulation under $\mathrm{NaCl}$ and mannitol stress conditions. Both salt and mannitol stresses have increased $\mathrm{H}_{2} \mathrm{O}_{2}$ accompanied by accumulation of proline. They also found out that dimethylthiourea (a scavenger of $\mathrm{H}_{2} \mathrm{O}_{2}$ ) and diphenylene iodonium (an inhibitor of $\mathrm{H}_{2} \mathrm{O}_{2}$ production by NADPH oxidase) inhibited P5CS activity and proline accumulation under these stresses. Supporting this phenomenon, evidence was also presented in Arabidopsis thaliana knockout mutants lacking either AtRboHD or AtRbohF. Wild-type plants accumulated more proline than these mutants (Ben Rejeb et al., 2015). These results suggest that Rbohs contribute to $\mathrm{H}_{2} \mathrm{O}_{2}$ production in response to salt and mannitol stresses and help in proline accumulation in Arabidopsis.

Some of the sugars like trehalose (a nonreducing disaccharide) also protect the plants against oxygen radicals. Cell lines defective in trehalose synthesis were more sensitive to oxygen radicals than the wild-type indicating that trehalose protected the plants against oxidative stress. Oxygen radicals damage the amino acids in cellular proteins, but trehalose in the cells prevented this damage indicating that trehalose acts as a free radical scavenger. Hincha et al. (2002) also pointed out that when trehalose is present in high concentrations in cells, plants show resistance to heat, dehydration, and oxygen stress. Galactose as well as mannitol protected the cells, but not sucrose since sucrose does not have the ability to quench oxygen radicals (Benaroudj et al., 2001). Depending upon the species, many plants display high plasticity to accumulate various kinds of sugars (levels may vary in cells depending on the stage of the growth, nutritional status, and environmental conditions prevailing at that time) like raffinose series (Gala-1-6-sucrose and higher), stachyose, and other sucrose oligosaccharides that give protection against different stress conditions. While mannitol may function to shield susceptible thiol-regulated enzymes (such as phosphoribulokinase) from inactivation by hydroxyl radicals in plants, GB is not effective as a hydroxy radical scavenger (Shen et al., 1997; Smirnoff and Cumbes, 1989). Thus, several lines of research clearly indicate the ROS scavenging functions of osmolytes, but the exact molecular mechanisms are not yet completely known.

\subsubsection{Osmolytes and Amelioration of $\mathrm{NaCl}$ - and Metal-Induced $\mathrm{K}^{+}$Efflux Under Stress}

Potassium $\left(\mathrm{K}^{+}\right)$homeostasis plays a central role during salt stress tolerance in the plant systems (Tester and Davenport, 2003). When plants are exposed to $\mathrm{NaCl}$ stress, a massive efflux of $\mathrm{K}^{+}$from plant cells is observed (Shabala et al., 2003; Chen et al., 2005). Prevention or mitigation of $\mathrm{K}^{+}$efflux is well correlated to salt stress tolerance in barley (Carden et al., 2003; Chen et al., 2005). It was not known until recently that compatible solutes are implicated with the $\mathrm{K}^{+}$transport under salt stress. Cuin and Shabala (2005) hypothesized that osmoprotectants may maintain cytosolic $\mathrm{K}^{+}$homeostasis by preventing $\mathrm{NaCl}$ induced $\mathrm{K}^{+}$leakage from the barley cells. They showed that either proline or GB at a concentration of $0.5-5 \mathrm{mM}$, when supplied exogenously, instantaneously reduced the $\mathrm{NaCl}$-induced $\mathrm{K}^{+}$efflux from barley roots in a dose dependent manner. Proline at $5-\mathrm{mM}$ concentrations reduced the hydroxyl-radical induced $\mathrm{K}^{+}$efflux in barley (Cuin and Shabala, 2007a). They also measured membrane potentials in addition to $\mathrm{K}^{+}$and $\mathrm{Na}^{+}$concentrations, which are consistent with the concept that cytosolic $\mathrm{K}^{+}$homeostasis is maintained by proline by preventing $\mathrm{NaCl}-$ induced leakage of $\mathrm{K}^{+}$from the cells. Proline may possibly control this through the increased activity of $\mathrm{H}^{+}$-ATPase, controlling voltage-dependent outward-rectifying $\mathrm{K}^{+}$channels and creating the electrochemical gradient that is essential for ion transport processes (Cuin and Shabala, 2005). Thus, evidence has been provided for the first time for the regulation of ion fluxes across the plasma membrane by addition of proline/osmolytes. Cuin and Shabala (2007b) further showed that 21 out of 26 amino acids tested caused a significant mitigation of the $\mathrm{NaCl}$-induced $\mathrm{K}^{+}$efflux. Surprisingly, both valine and ornithine prevented the $\mathrm{NaCl}$-induced $\mathrm{K}^{+}$efflux significantly along with proline and maintained $\mathrm{K}^{+}$homeostasis. They pointed out that physiologically relevant concentrations of amino acids might contribute to salt stress adaptation by regulating $\mathrm{K}^{+}$transport across the plasma membrane. This might perhaps help the plants to maintain optimal $\mathrm{K}^{+} / \mathrm{Na}^{+}$ratio, which is vital during salt stress. But, the exact mechanism underlying proline prevented $\mathrm{K}^{+}$efflux under stress is not known. Still though it is thought that free radicals can mediate this. Heavy metals such as $\mathrm{Cu}^{2+}$ when added to lower plants (algal members) also cause leakage of $\mathrm{K}^{+}$from the cells. Whether proline or other osmolytes are associated with $\mathrm{Cu}^{2+} /$ metal-induced $\mathrm{K}^{+}$leakage prevention in metal tolerant plants is not known.

\subsubsection{Osmolytes and Their Metal Chelation Properties During Metal Stress}

Several crop plants (Cajanus cajan, Vigna mungo, Triticum aestivum) accumulate proline in response to heavy metal stress (Alia and Saradhi, 1991; Bassi and Sharma, 1993). In seedlings of Oryza sativa, exogenous 
supply of proline reduced the copper uptake (Chen et al., 2004). They noticed that proline supplement accompanied by $\mathrm{Cu}^{2+}$ exposure induce a barrier of $\mathrm{Cu}^{2+}$ influx and efflux in rice roots. It appeared that excess $\mathrm{Cu}^{2+}$ leads to inadequate proline in rice roots and results in the malfunction of copper transport barrier. An increase up to $>20$-fold in the proline content was noticed in leaves of metal nontolerant Silene vulgaris (Schat et al., 1997). The shoot proline content is higher than that in roots in Silene. On the other hand, root proline levels increased in Lactuca sativa with an increase in cadmium concentration (Costa and Morel, 1994). Not only nonmetal-tolerant plants, but also several metal-tolerant species like Armeria maritima, Deschampsia cespitosa, and Silene vulgaris have been reported to contain substantially higher constitutive proline levels when compared with nontolerant relatives (Farago and Mullen, 1979; Smirnoff and Stewart, 1987; Schat et al., 1997). But A. maritima plants, when grown in a noncopper site did not exhibit higher proline content (Farago and Mullen, 1979). Proline also accumulated in lower plants like algal members (Anacystis, Chlorella, Scendesmus, etc.) when exposed to heavy metal stress (Wu et al., 1995, 1998; Tripathi and Gaur, 2004). Thus, a large body of information existed with regard to proline accumulation under metal stress. Costa and Morel (1994) suggested that inhibition of proline oxidation is the reason for higher root proline levels under metal stress. Chen et al. (2001) pointed out that increased P5CR or OAT activities are responsible for higher proline accumulation in rice. Since water balance is disturbed under heavy metal stress, it is reasonable to speculate an increased proline synthesis and accumulation (Barceló and Poschenrieder, 1990). Chen et al. (2001) also suggested ABA mediated $\mathrm{Cu}$-induced proline accumulation in rice leaves. Later, it has been reported that copperinduced proline synthesis in the green algal member Chlamydomonas reinhardtii is associated with NO generation. They further investigated the effect of $\mathrm{Cu}^{2+}$ and NO on the activity and transcript amount of P5CS, and observed that application of sodium nitroprusside (NO specific donor) is able to stimulate the P5CS activity in the Cu-treated algae (Zhang et al., 2008). Their results indicated that $\mathrm{Cu}$-responsive proline synthesis is related to $\mathrm{NO}$ generation in C. reinhardtii.

Based on the existing information, the following speculations can be drawn for the possible metal stress mitigation by proline/osmolytes in plants. Proline may be acting as a metal chelator as demonstrated by Farago and Mullen (1979). They showed that $\mathrm{Cu}^{2+}$ in the roots of A. maritima existed as $\mathrm{Cu}$-proline complex. Proline protected glucose-6-phosphate dehydrogenase and nitrate reductase activities in vitro against zinc and copper-induced inhibition due to the formation of a metal-proline complex (Sharma et al., 1998). Experiments conducted by Siripornadulsil et al. (2002) contradict these results. Their experiments revealed that transgenic Chlamydomonas reinhardtii expressing the mothbean P5CS gene exhibits tolerance to $100 \mu \mathrm{M}$ cadmium and has $80 \%$ higher proline levels than the wild-type cells. They observed that cadmium does not bind to proline in transgenic algae but is coordinated tetrahedrally by sulfur of phytochelatin. In contrast to P5CS-expressing cells, in wild-type cells, cadmium is coordinated tetrahedrally by two oxygen and two sulfur atoms. These results suggested that free proline acts as an antioxidant in cadmium-stressed cells with higher reduced glutathione (GSH) levels. Enhanced GSH levels in turn facilitate phytochelatin synthesis and sequestration of cadmium, since GSH-heavy metal adducts are the substrates for phytochelatin synthase, as pointed out by Siripornadulsil et al. (2002). The above fact that cadmium is coordinated by oxygen and sulfur atoms supported the findings of Adhiya et al. (2002). Proline chelation of cadmium does not seem to be important since cadmium induces phytochelatins that can chelate the metal (de Knecht et al., 1994). Therefore, it is of interest to find out the role of proline or other osmolytes in binding metal ions that do not form complexes with phytochelatins as has been also pointed out by Sharma and Dietz (2006). The second possibility is that proline may be acting as an antioxidant during metal stress. Free radicals are generated under heavy metal stress, which could lead to oxidative stress. As mentioned in the earlier sections, both ${ }^{1} \mathrm{O}_{2}$ and $\mathrm{OH}^{-}$can be scavenged by proline. Heavy metal exposure causes lipid peroxidation as well as $\mathrm{K}^{+}$ efflux in algal members. Wu et al. (1995) observed that when Anacystis nidulans (Cyanobacteria) was exposed to $\mathrm{Cu}^{2+}, \mathrm{K}^{+}$is effluxed out, but exogenously supplied proline reduced the leakage. Wu et al. (1998) also noticed that when proline was supplied exogenously to Chlorella species prior to copper treatment, it resulted in desorption of the adsorbed $\mathrm{Cu}^{2+}$ immediately after the addition of proline. These results indicate that one function of accumulated proline is to reduce the uptake of metal ions. Mehta and Gaur (1999) reported that Chlorella vulgaris accumulates proline within few hours of exposure to a wide range of heavy metals. Their experiments demonstrate that pretreatment of $C$. vulgaris with proline counteract metalinduced lipid peroxidation as well as $\mathrm{K}^{+}$efflux. Even in lichens Trebouxia erici (Bačkor et al., 2004), proline content is positively correlated to $\mathrm{Cu}^{2+}$ tolerance. Taken together, it is unlikely that proline binds to metals and chelates them during metal stress, but preferentially acts as an antioxidant molecule and detoxifies the ROS. 


\subsubsection{Role of Osmolytes in Membrane and Native Protein Structure Stabilizations}

Galinski (1993) noticed thermal stability of enzymes in the presence of osmolytes. Several other lines of evidence show that osmolytes effectively protect plant enzymes against stress induced denaturation (Solomon et al., 1994; Yang et al., 2007). Arguments and counterarguments were raised against and in favor of the effective compatible solute concentrations that are needed for protection of enzymes in vitro. While $500 \mathrm{mM}$ has been suggested as an effective concentration for membrane stability, such high concentrations are often not detected in vivo (Bohnert and Shen, 1998). It appears that the osmolyte concentration may not be important since Zhao et al. (1992) have shown protection of thylakoid and plasma membranes against freezing damage under high as well as low concentrations. Experiments conducted to date indicate that the local concentration of membrane or protein surfaces is vital rather than the absolute concentrations for membrane stabilization or enzyme protection in plants undergoing stress.

Fructans are a class of polysaccharides known for their protective effects on liposomes during conditions of drying. Both bacteria (levan produced from Bacillus subtilis) and plants (inulin synthesized from chicory roots) have been found to protect liposomes from leakage during freeze-drying or air-drying (Hincha et al., 2000; Vereyken et al., 2003). Besides chicory, many grass species also accumulate osmolytes like fructans (Livingston et al., 2009). Differences exist between fruc$\tan$ molecules in their size, structure, and also tissue localization, which is vital for the survival of the whole plants under cold stress conditions (Livingston et al., 2005, 2006). Hincha et al. (2000) showed that inulin is a mixture of polysaccharides with a degree of polymerization (DP) between 10 and 30 (Hincha et al., 2000) and molecular masses 1600 and 5000. These researchers pointed out that during freeze-drying, inulin in phosphatidylcholine liposome preparations reduces the degree of leakage after rehydration by establishing $\mathrm{H}$-bonds to the lipid $\mathrm{P}=\mathrm{O}$. But, high-DP fructans from oat and rye are not able to prevent leakage or fusion in liposomes during drying (Hincha et al., 2007). On the other hand, inulins and fructans from the same species with 7-10 degrees of polymerization (more soluble) do not precipitate during air-drying and provide protection to liposomes (Hincha et al., 2002, 2007; Vereyken et al., 2003). It appears that fructans are transported in the phloem of Agave deserti leaf tissues (Wang and Nobel, 1998). Similarly, it has been found that fructan DP3 is transported via the apoplast (phloem) in transgenic potato inferring that fructans in the apoplast protect the tissues from freezing/dehydration injury besides serving as a hexose reserve (Zuther et al., 2004). Levan from Bacillus subtilis has a DP of about 125, found to have higher solubility, but protects liposomes from leakage and fusion (Vereyken et al., 2003). Taken together, it appears that specific structural features of oligosaccharides determine their efficacy as membrane stabilizers during drying/ freezing stress.

Some plants, especially anhydrobiotic organisms produce very high concentrations of trehalose, and other di- and oligosaccharides under abiotic stress conditions (Zentella et al., 1999; Elbein et al., 2003). In plants, sucrose also plays a similar role to that of trehalose in yeast (Anandarajah and McKersie, 1990). A large body of evidence suggests that trehalose, due to its structure and stereochemistry, depresses the phase transition temperature of the dry lipids, which maintains them in the liquid crystalline phase in the absence of water (Crowe and Crowe, 1988). Trehalose appears to preserve labile proteins during drying probably by interacting directly with the dry protein by hydrogen bonding between its hydroxyl groups and polar residues in the protein (Carpenter and Crowe, 1989). Two contrasting models that have been proposed to explain protective or stabilizing effects of compatible solutes on membrane/protein structures are (1) the preferential exclusion model (Arakawa and Timasheff, 1985) and (2) the preferential interaction model. In the first model, compatible solutes are excluded from the hydration shell of proteins that stabilize protein structure or promote protein/protein interaction under stress. But, Schobert (1977) is of the opinion that interactions between the compatible solutes and proteins are necessary, and protein's hydration shell is crucial for its structural stability. It appears that osmolytes interact with the hydrophobic domains of proteins and prevent their destabilization. The molecular mechanism for osmolyte-induced protein stability has been elucidated by Street et al. (2006). They pointed out that in the equilibrium protein folding reaction, unfolded $(\mathrm{U}) \leftrightarrow$ native $(\mathrm{N})$, high concentrations of protecting osmolytes push the equilibrium of protein folding towards $\mathrm{N}$, while denaturing osmolytes push it toward the unfolded form (U). It appears that the configuration of the protein backbone is the most important determinant of stabilization or denaturation. As yet, there is no universal molecular theory that explains the mechanism by which osmolytes interact with the protein to alter its stability in higher plants under abiotic stress conditions. However, more experiments will be necessary to gain a better insight into the membrane/protein stabilizing effects of osmolytes. 


\subsubsection{Osmolytes as Sources of Energy and Carbon Reserve During and After the Release of Stress}

It is interesting to note that drought, salt, and flooding stresses increase generally soluble sugar concentrations in plants, but high light intensity, heavy metals, and ozone decrease sugar accumulation depending on the genotype (Gill et al., 2001; Morsy et al., 2007). It is possible that not all soluble sugars play identical roles during stress (Almodares et al., 2008). If sugars are accumulated in high concentrations, that can lead to downregulation of further energy synthesis (Koch, 2004; Chen, 2007). While low sugar content in the tissues increases photosynthesis, high sugar level promotes carbohydrate storage. Thus, changes in $\mathrm{CO}_{2}$ assimilation are possible by sugar accumulation under stress. This is one of the ways perhaps to maintain energy homeostasis in plants during abiotic stress conditions as has been pointed out by Rosa et al. (2009a). Gupta and Kaur (2005) described that both glucose and sucrose act as sources of carbon and energy, but also as osmolytes (but not fructose) to maintain cell homeostasis. Oxidation of sugars via glycolytic and other pathways leads to the production of ATP, NADPH, and erythrose-4-phosphate, which can be utilized once the stress is released. Osmolytes like proline are involved in the alleviation of cytoplasmic acidosis and sustaining $\mathrm{NADP}^{+} / \mathrm{NADPH}$ ratios at the levels required for metabolism (Hare and Cress, 1997). The functions of proline are dependent on spatial and temporal control of its synthesis as well as its catabolism. In turn, this helps the plants either to take up or release reductant and energy at a site/tissue location where it is necessary for metabolic functions (Sharma et al., 2011). Plants prefer NADPH over NADH as an electron donor for the biosynthesis of proline (Murahama et al., 2001). This helps the plants to regenerate $\mathrm{NADP}^{+}$in the chloroplast and thus prevents ROS production and photoinhibition as has been pointed out by Szabados and Savoure (2010). The work of Sharma et al. (2011) demonstrated that both p5cs1 (involved in proline synthesis) and pdh1 mutants (blocked in proline catabolism) are required for optimal growth at low water potential. Many lines of evidence suggest that the generation of $\mathrm{NADP}^{+}$and $\mathrm{NADPH}$ during proline synthesis and degradation respectively and maintaining a favorable ratio of $\mathrm{NADP}^{+}$/NADPH are also critical for the survival of plants under stress. Once the stress is relieved, accumulated proline is oxidized in mitochondria and energy is released. Both proline and trehalose (Becker et al., 1996) are the major sugars and are consumed during flight in insects. Thornburg (2007) analyzed the content of proline in ornamental tobacco (LxS8 line) flowers, which was $2020 \mu \mathrm{M}$, while the concentration of other amino acids are in the range of only $114-547 \mu \mathrm{M}$. Bertazzini et al. (2010) found that artificial nectar containing proline is preferred by forager honeybees. Trehalose is stored in fungal spores and its hydrolysis helps in spore germination and is a source of carbon for synthesis of glucose (Thevelein, 1984). Thus, osmolytes act as both as a source of carbon and energy during and after release from the stress conditions.

\subsection{OSMOLYTES AND SIGNALING PROCESSES}

\subsubsection{Proline and Signaling Processes}

Proline propels two major signaling events like cellular survival as well as apoptosis. During proline oxidation, ROS are formed in the mitochondria, which have been implicated in the hypersensitive response in plants. Further, ROS leads to induction of intrinsic and extrinsic apoptotic cell death pathways in animals (Liu et al., 2006; Hu et al., 2007). Thus, ROS appear to be the main signal transducers for downstream responses during proline oxidation. However, several critical issues remain elusive in our understanding of these events. First, is there any threshold level of proline that is required for metabolic switchover from inducing survival pathways to cellular apoptosis? Second, it is not known if there are any other mediators or components that are associated with signaling phenomena during proline metabolism. Existing evidence suggests that proline biosynthetic pathway enzymes interact with redox proteins like thioredoxin (Liang et al., 2013). It would be interesting to find out if there are any other interacting partners of proline metabolic enzymes that play a role in cellular signaling networks leading to the triggering of downstream events.

\subsubsection{Proline Metabolism and Signaling Pathways in Plant Senescence}

Proline is also associated with plant senescence. Nearly 14-fold increase in proline content was recorded in petals of cut roses during the process of senescence. Enhanced activities of P5CS and ProDH were also noticed during the course of senescence (Kumar et al., 2009). While the expression of ProDH2 in the vascular tissue and abscission zone of petals is regulated by the transcription factor bZIP11 (Hanson et al., 2008), ProDH1 expression is modulated by bZIP1 and bZIP53 (Dietrich et al., 2011) in Arabidopsis thaliana. This infers that proline is catabolized rapidly 
whenever sucrose levels are low in plants (Funck et al., 2010; Llorca et al., 2014). During senescence, proline metabolism also influences ROS signaling pathways that delay the process of senescence (Zhang and Becker, 2015). But, more studies are needed on the regulation of proline metabolic shifts that occur during senescence. Such studies may provide novel insights that rescue crop plants undergoing abiotic stress and also preserve postharvest agricultural products.

\subsubsection{Osmolytes as Sensing Compounds and/or Growth Regulators}

Sugars such as glucose and sucrose may act as sources of carbon and energy. But, fructose plays a different role from that of glucose and sucrose. Hilal et al. (2004) demonstrated that fructose acts as a precursor for the synthesis of lignin and several phenolic compounds, thus inferring that sugar accumulation under stress performs diverse roles. Sugars can act as primary messengers and regulate signals that control the expressions of genes (Gupta and Kaur, 2005; Gibson, 2005; Chen, 2007). Since sugars are rapidly metabolized and also interconverted depending upon the environmental stresses (Rosa et al., 2009b), it is difficult to pinpoint if sensing of soluble sugars depends upon their metabolism. But, it is known that sugar levels modulate differential expression of genes (Koch et al., 1992). Rook et al. (1998) demonstrated that sucrose-specific signaling pathways to be responsible for repression of ATB2bZIP transcription factor. Many genes are negatively regulated by sugars (sucrose, glucose, and fructose) at the transcription level (Yamaguchi-Shinozaki and Shinozaki, 2006). When $30 \mathrm{mM}$ proline was applied exogenously, it ameliorated the salt stress effects in rice, but $40-50 \mathrm{mM}$ levels resulted in poor growth (Roy et al., 1993). Overexpression of microbial genes for trehalose biosynthesis caused dwarfism and aberrant root development (Vogel et al., 1998). Müller et al. (1999) found such growth defects in transgenic rice producing trehalose. These findings have led to postulate that osmolytes might function as plant growth regulators. The plausible explanation that has been given is that small amounts of trehalose or trehalose-phosphate might be toxic to the plants. Else, trehalose metabolism may act as a signal in sugar sensing and partitioning of assimilates like other sugars (Müller et al., 1999).

\subsection{CONCLUSIONS AND FUTURE PROSPECTS}

ABA is central to the signal perception and subsequent transduction events during abiotic stress. The core signaling module regulates several downstream events including osmolyte biosynthesis and subsequently abiotic stress tolerance. Diverse osmolytes accumulated during abiotic stress conditions are regulated by many phytohormones. Osmolytes perform many vital functions such as osmotic adjustment, scavenging ROS, controlling the redox state, and cell survival and apoptosis during stress. However, the precise molecular mechanisms underlying the triggering of genes associated with several of the osmolyte biosyntheses and catabolisms (barring a few) are not completely known. Therefore, it is of prime importance to unravel the intricate networks, molecular mechanisms, and the signaling events leading to the better survival of crop plants exposed to different abiotic stress conditions. Such a comprehensive knowledge about molecular mechanisms and signaling events leading to the regulation of osmolyte biosynthesis and effective scavenging of ROS will enable us to develop strategies to genetically modify crop plants and use them for sustainable agricultural yields.

\section{Acknowledgments}

PBK is thankful for sanctioning CSIR-Emeritus Scientist Fellowship through the Grant Number 38(1325)/12/EMR-II) by the Council for Scientifics and Industrial Research, New Delhi.

\section{References}

Abrahám, E., Rigó, G., Székely, G., Nagy, R., Koncz, C., Szabados, L., 2003. Light-dependent induction of proline biosynthesis by abscisic acid and salt stress is inhibited by brassinosteroid in Arabidopsis. Plant Mol. Biol. 51 (3), 363-372.

Adhiya, J., Cai, X., Sayre, R.T., Traina, S.J., 2002. Binding of aqueous cadmium by the lyophilized biomass of Chlamydomonas reinhardtii. Colloids Surfaces A: Physicochem. Eng. Aspects 210 (1), $1-11$.

Aleksza, D., Horváth, G.V., Sándor, G., Szabados, L., 2017. Proline accumulation is regulated by transcription factors associated with phosphate starvation. Plant Physiol. 175 (1), 555-567.

Alia, Hayashi, H., Sakamoto, A., Murata, N., 1998. Enhancement of the tolerance of Arabidopsis to high temperatures by genetic engineering of the synthesis of glycinebetaine. Plant J. 16 (2), $155-161$.

Alia, Kondo, Y., Sakamoto, A., Nonaka, H., Hayashi, H., Saradhi, P. P., et al., 1999. Enhanced tolerance to light stress of transgenic Arabidopsis plants that express the codA gene for a bacterial choline oxidase. Plant Mol. Biol. 40 (2), 279-288.

Alia, Mohanty, P., Matysik, J., 2001. Effect of proline on the production of singlet oxygen. Amino Acids 21 (2), 195-200.

Alia, Saradhi, P.P., 1991. Proline accumulation under heavy metal stress. J. Plant. Physiol. 138 (5), 554-558.

Alia, Saradhi, P.P., Mohanty, P., 1997. Involvement of proline in protecting thylakoid membranes against free radical-induced photodamage. J. Photochem. Photobiol. B: Biol. 38 (2-3), 253-257.

Allakhverdiev, S.I., Los, D.A., Mohanty, P., Nishiyama, Y., Murata, N., 2007. Glycinebetaine alleviates the inhibitory effect of moderate heat stress on the repair of photosystem II during 
photoinhibition. Biochim. Biophys. Acta (BBA)-Bioenerg. 1767 (12), 1363-1371.

Almodares, A., Taheri, R., Chung, M., Fathi, M., 2008. The effect of nitrogen and potassium fertilizers on growth parameters and carbohydrate contents of sweet sorghum cultivars. J. Environ. Biol. 29 (6), 849-852.

Anandarajah, K., McKersie, B.D., 1990. Manipulating the desiccation tolerance and vigor of dry somatic embryos of Medicago sativa L. with sucrose, heat shock and abscisic acid. Plant Cell Rep. 9 (8), $451-455$.

Arakawa, T., Timasheff, S.N., 1985. The stabilization of proteins by osmolytes. Biophys. J. 47 (3), 411-414.

Aro, E.M., Virgin, I., Andersson, B., 1993. Photoinhibition of photosystem II. Inactivation, protein damage and turnover. Biochim. Biophys. Acta (BBA)-Bioenerg. 1143 (2), 113-134.

Arora, S., Saradhi, P.P., 2002. Light induced enhancement in proline levels under stress is regulated by non-photosynthetic events. Biol. Plant. 45 (4), 629-632.

Bačkor, M., Fahselt, D., Wu, C.T., 2004. Free proline content is positively correlated with copper tolerance of the lichen photobiont Trebouxia erici (Chlorophyta). Plant Sci. 167 (1), 151-157.

Barceló, J.U.A.N., Poschenrieder, C., 1990. Plant water relations as affected by heavy metal stress: a review. J. Plant. Nutr. 13 (1), $1-37$.

Bassi, R., Sharma, S.S., 1993. Proline accumulation in wheat seedlings exposed to zinc and copper. Phytochemistry 33 (6), 1339-1342.

Becker, A., Schlöder, P., Steele, J.E., Wegener, G., 1996. The regulation of trehalose metabolism in insects. Experientia 52 (5), 433-439.

Ben Rejeb, K., Vos, L.D., Le Disquet, I., Leprince, A.S., Bordenave, M., Maldiney, R., et al., 2015. Hydrogen peroxide produced by NADPH oxidases increases proline accumulation during salt or mannitol stress in Arabidopsis thaliana. New Phytol. 208 (4), $1138-1148$.

Benaroudj, N., Lee, D.H., Goldberg, A.L., 2001. Trehalose accumulation during cellular stress protects cells and cellular proteins from damage by oxygen radicals. J. Biol. Chem. 276 (26), 24261-24267.

Bertazzini, M., Medrzycki, P., Bortolotti, L., Maistrello, L., Forlani, G., 2010. Amino acid content and nectar choice by forager honeybees (Apis mellifera L.). Amino Acids 39 (1), 315-318.

Blokhina, O., Virolainen, E., Fagerstedt, K.V., 2003. Antioxidants, oxidative damage and oxygen deprivation stress: a review. Ann. Bot. (Lond.) 91 (2), 179-194.

Bohnert, H.J., Shen, B.O., 1998. Transformation and compatible solutes. Sci. Hortic. (Amsterdam) 78 (1-4), 237-260.

Borowitzka, L.J., Brown, A.D., 1974. The salt relations of marine and halophilic species of the unicellular green alga. Dunaliella. Arch. Microbiol. 96 (1), 37-52.

Boudsocq, M., Droillard, M.J., Barbier-Brygoo, H., Laurière, C., 2007. Different phosphorylation mechanisms are involved in the activation of sucrose non-fermenting 1 related protein kinases 2 by osmotic stresses and abscisic acid. Plant Mol. Biol. 63 (4), 491-503.

Brown, A.D., Simpson, J.R., 1972. Water relations of sugar-tolerant yeasts: the role of intracellular polyols. Microbiology 72 (3), 589-591.

Carden, D.E., Walker, D.J., Flowers, T.J., Miller, A.J., 2003. Single-cell measurements of the contributions of cytosolic $\mathrm{Na}^{+}$and $\mathrm{K}^{+}$to salt tolerance. Plant Physiol. 131 (2), 676-683.

Carpenter, J.F., Crowe, J.H., 1989. An infrared spectroscopic study of the interactions of carbohydrates with dried proteins. Biochemistry 28 (9), 3916-3922.

Chen, C.T., Chen, L.M., Lin, C.C., Kao, C.H., 2001. Regulation of proline accumulation in detached rice leaves exposed to excess copper. Plant Sci. 160 (2), 283-290.
Chen, C.T., Chen, T.H., Lo, K.F., Chiu, C.Y., 2004. Effects of proline on copper transport in rice seedlings under excess copper stress. Plant Sci. 166 (1), 103-111.

Chen, J.G., 2007. Sweet sensor, surprising partners. Sci. STKE 2007 (373), pp.pe7-pe7.

Chen, Z., Newman, I., Zhou, M., Mendham, N., Zhang, G., Shabala, S., 2005. Screening plants for salt tolerance by measuring $\mathrm{K}+$ flux: a case study for barley. Plant Cell Environ. 28 (10), 1230-1246.

Chen, J., Shang, Y.T., Wang, W.H., Chen, X.Y., He, E.M., Zheng, H. L., et al., 2016. Hydrogen sulfide-mediated polyamines and sugar changes are involved in hydrogen sulfide-induced drought tolerance in Spinacia oleracea seedlings. Front. Plant Sci. 7, 1173.

Costa, G., Morel, J.L., 1994. Water relations, gas exchange and amino acid content in Cd-treated lettuce. Plant. Physiol. Biochem. (France).

Crowe, L.M., Crowe, J.H., 1988. Trehalose and dry dipalmitoylphosphatidylcholine revisited. Biochim. Biophys. Acta (BBA)-Biomembr. 946 (2), 193-201.

Cuin, T.A., Shabala, S., 2005. Exogenously supplied compatible solutes rapidly ameliorate $\mathrm{NaCl}$-induced potassium efflux from barley roots. Plant Cell Physiol. 46 (12), 1924-1933.

Cuin, T.A., Shabala, S., 2007a. Compatible solutes reduce ROSinduced potassium efflux in Arabidopsis roots. Plant Cell Environ. 30 (7), 875-885.

Cuin, T.A., Shabala, S., 2007b. Amino acids regulate salinity-induced potassium efflux in barley root epidermis. Planta 225 (3), $753-761$.

Cutler, S.R., Rodriguez, P.L., Finkelstein, R.R., Abrams, S.R., 2010. Abscisic acid: emergence of a core signaling network. Annu. Rev. Plant. Biol. 61, 651-679.

Davies, K.J., 1987. Protein damage and degradation by oxygen radicals. I. general aspects. J. Biol. Chem. 262 (20), 9895-9901.

de Campos, M.K.F., de Carvalho, K., de Souza, F.S., Marur, C.J., Pereira, L.F.P., Bespalhok Filho, J.C., et al., 2011. Drought tolerance and antioxidant enzymatic activity in transgenic 'Swingle'citrumelo plants over-accumulating proline. Environ. Exp. Bot. 72 (2), 242-250.

de Knecht, J.A., van Dillen, M., Koevoets, P.L., Schat, H., Verkleij, J. A., Ernst, W.H., 1994. Phytochelatins in cadmium-sensitive and cadmium-tolerant Silene vulgaris (chain length distribution and sulfide incorporation). Plant Physiol. 104 (1), 255-261.

Delauney, A.J., Hu, C.A., Kishor, P.B., Verma, D.P., 1993. Cloning of ornithine delta-aminotransferase cDNA from Vigna aconitifolia by trans-complementation in Escherichia coli and regulation of proline biosynthesis. J. Biol. Chem. 268 (25), 18673-18678.

Desikan, R., Griffiths, R., Hancock, J., Neill, S., 2002. A new role for an old enzyme: nitrate reductase-mediated nitric oxide generation is required for abscisic acid-induced stomatal closure in Arabidopsis thaliana. Proc. Natl. Acad. Sci. 99 (25), 16314-16318.

Dietrich, K., Weltmeier, F., Ehlert, A., Weiste, C., Stahl, M., Harter, K., et al., 2011. Heterodimers of the Arabidopsis transcription factors bZIP1 and bZIP53 reprogram amino acid metabolism during low energy stress. Plant Cell 23 (1), 381-395.

Elbein, A.D., Pan, Y.T., Pastuszak, I., Carroll, D., 2003. New insights on trehalose: a multifunctional molecule. Glycobiology 13 (4), 17R-27R.

El-Tayeb, M.A., 2005. Response of barley grains to the interactive effect of salinity and salicylic acid. Plant Growth Regul. 45 (3), $215-224$.

Fabro, G., Kovacs, I., Pavet, V., Szabados, L., Alvarez, M.E., 2004. Proline accumulation and AtP5CS2 gene activation are induced by plant-pathogen incompatible interactions in Arabidopsis. Mol. Plant-Microbe Interact. 17, 343-350.

Farago, M.E., Mullen, W.A., 1979. Plants which accumulate metals. Part IV. A possible copper-proline complex from the roots of Armeria maritima. Inorganica. Chim. Acta 32, L93-L94. 
Fedina, I.S., Grigorova, I.D., Georgieva, K.M., 2003. Response of barley seedlings to UV-B radiation as affected by $\mathrm{NaCl}$. J. Plant. Physiol. 160 (2), 205-208.

Feng, X.J., Li, J.R., Qi, S.L., Lin, Q.F., Jin, J.B., Hua, X.J., 2016. Light affects salt stress-induced transcriptional memory of P5CS1 in Arabidopsis. Proc. Natl. Acad. Sci. 113 (51), E8335-E8343.

Flowers, T.J., Hall, J.L., 1978. Salt tolerance in the halophyte, Suaeda maritima (L.) Dum.: the influence of the salinity of the culture solution on the content of various organic compounds. Ann. Bot. (Lond.) 42 (5), 1057-1063.

Fujii, H., Chinnusamy, V., Rodrigues, A., Rubio, S., Antoni, R., Park, S.Y., et al., 2009. In vitro reconstitution of an abscisic acid signalling pathway. Nature 462 (7273), 660-664.

Funck, D., Eckard, S., Müller, G., 2010. Non-redundant functions of two proline dehydrogenase isoforms in Arabidopsis. BMC Plant Biol. 10 (1), 70.

Galinski, E.A., 1993. Compatible solutes of halophilic eubacteria: molecular principles, water-solute interaction, stress protection. Experientia 49 (6-7), 487-496.

Gao, X.P., Pan, Q.H., Li, M.J., Zhang, L.Y., Wang, X.F., Shen, Y.Y., et al., 2004b. Abscisic acid is involved in the water stress-induced betaine accumulation in pear leaves. Plant Cell Physiol. 45 (6), $742-750$.

Gao, X.P., Wang, X.F., Lu, Y.F., Zhang, L.Y., Shen, Y.Y., Liang, Z., et al., 2004a. Jasmonic acid is involved in the water-stress-induced betaine accumulation in pear leaves. Plant Cell Environ. 27 (4), 497-507.

Gibson, S.I., 2005. Control of plant development and gene expression by sugar signaling. Curr. Opin. Plant. Biol. 8 (1), 93-102.

Gill, P.K., Sharma, A.D., Singh, P., Bhullar, S.S., 2001. Effect of various abiotic stresses on the growth, soluble sugars and water relations of sorghum seedlings grown in light and darkness. Bulg. J. Plant Physiol 27 (1-2), 72-84.

Gorham, J., 1995. Betaine in higher plants- biosynthesis and role in stress metabolism. In: Wallsgrove, R.M. (Ed.), Amino Acids in Higher Plants. Cambridge University Press, Cambridge, pp. 171-203.

Gupta, A.K., Kaur, N., 2005. Sugar signalling and gene expression in relation to carbohydrate metabolism under abiotic stresses in plants. J. Biosci. 30 (5), 761-776.

Hai-Hua, R., Wen-Biao, S., Lang-Lai, X., 2004. Nitric oxide involved in the abscisic acid induced proline accumulation in wheat seedling leaves under salt stress. Acta Botanica Sinica 46 (11), 1307-1315.

Haldimann, P., Feller, U., 2005. Growth at moderately elevated temperature alters the physiological response of the photosynthetic apparatus to heat stress in pea (Pisum sativum L.) leaves. Plant Cell Environ. 28 (3), 302-317.

Hallouin, M., Ghelis, T., Brault, M., Bardat, F., Cornel, D., Miginiac, E., et al., 2002. Plasmalemma abscisic acid perception leads to RAB18 expression via phospholipase D activation in Arabidopsis suspension cells. Plant Physiol. 130 (1), 265-272.

Hanson, J., Hanssen, M., Wiese, A., Hendriks, M.M., Smeekens, S., 2008. The sucrose regulated transcription factor bZIP11 affects amino acid metabolism by regulating the expression of Asparagine synthetase 1 and Proline dehydrogenase2. Plant J. 53 (6), 935-949.

Hare, P.D., Cress, W.A., 1997. Metabolic implications of stressinduced proline accumulation in plants. Plant Growth Regul. 21 (2), 79-102.

Hare, P.D., Cress, W.A., Van Staden, J., 1998. Dissecting the roles of osmolyte accumulation during stress. Plant Cell Environ. 21 (6), 535-553.

Hare, P.D., Cress, W.A., Van Staden, J., 1999. Proline synthesis and degradation: a model system for elucidating stress-related signal transduction. J. Exp. Bot. 50 (333), 413-434.
Hasanuzzaman, M., Alam, M., Rahman, A., Hasanuzzaman, M., Nahar, K., Fujita, M., 2014. Exogenous proline and glycine betaine mediated upregulation of antioxidant defense and glyoxalase systems provides better protection against salt-induced oxidative stress in two rice (Oryza sativa L.) varieties. Biomed. Res. Int. 2014.

Hayashi, H., Sakamoto, A., Murata, N., 1998. Enhancement of the tolerance of Arabidopsis to high temperatures by genetic engineering of the synthesis of glycinebetaine. Plant J. 16 (2), 155-161.

Hayashi, F., Ichino, T., Osanai, M., Wada, K., 2000. Oscillation and regulation of proline content by P5CS and ProDH gene expressions in the light/dark cycles in Arabidopsis thaliana L. Plant Cell Physiol. 41 (10), 1096-1101.

He, H., He, L.F., 2017. Regulation of gaseous signaling molecules on proline metabolism in plants. Plant Cell Rep. 37 (3), 387-392.

Henson, I.E., 1984. Effects of atmospheric humidity on abscisic acid accumulation and water status in leaves of rice (Oryza sativa L.). Ann. Bot. (Lond.) 54 (4), 569-582.

Hilal, M., Parrado, M.F., Rosa, M., Gallardo, M., Orce, L., Massa, E. M., et al., 2004. Epidermal lignin deposition in quinoa cotyledons in response to UV-B radiation. Photochem. Photobiol. 79 (2), 205-210

Hincha, D.K., Hellwege, E.M., Heyer, A.G., Crowe, J.H., 2000. Plant fructans stabilize phosphatidylcholine liposomes during freezedrying. FEBS. J. 267 (2), 535-540.

Hincha, D.K., Zuther, E., Hellwege, E.M., Heyer, A.G., 2002. Specific effects of fructo-and gluco-oligosaccharides in the preservation of liposomes during drying. Glycobiology 12 (2), 103-110.

Hincha, D.K., Livingston, D.P., Premakumar, R., Zuther, E., Obel, N., Cacela, C., et al., 2007. Fructans from oat and rye: composition and effects on membrane stability during drying. Biochim. Biophys. Acta (BBA)-Biomembr. 1768 (6), 1611-1619.

Holmström, K.O., Somersalo, S., Mandal, A., Palva, T.E., Welin, B., 2000. Improved tolerance to salinity and low temperature in transgenic tobacco producing glycine betaine. J. Exp. Bot. 51 (343), 177-185.

Hoque, M.A., Banu, M.N.A., Okuma, E., Amako, K., Nakamura, Y., Shimoishi, Y., et al., 2007b. Exogenous proline and glycinebetaine increase $\mathrm{NaCl}$-induced ascorbate-glutathione cycle enzyme activities, and proline improves salt tolerance more than glycinebetaine in tobacco bright yellow-2 suspension-cultured cells. J. Plant. Physiol. 164 (11), 1457-1468.

Hoque, M.A., Okuma, E., Banu, M.N.A., Nakamura, Y., Shimoishi, Y., Murata, Y., 2007a. Exogenous proline mitigates the detrimental effects of salt stress more than exogenous betaine by increasing antioxidant enzyme activities. J. Plant. Physiol. 164 (5), $553-561$.

Hu, C.A., Donald, S.P., Yu, J., Lin, W.W., Liu, Z., Steel, G., et al., 2007. Overexpression of proline oxidase induces prolinedependent and mitochondria-mediated apoptosis. Mol. Cell. Biochem. 295 (1-2), 85-92.

Huang, Z., Zhao, L., Chen, D., Liang, M., Liu, Z., Shao, H., et al., 2013. Salt stress encourages proline accumulation by regulating proline biosynthesis and degradation in Jerusalem artichoke plantlets. PLoS One 8 (4), e62085.

Hüner, N., Dahal, K., Kurepin, L.V., Savitch, L., Singh, J., Ivanov, A. G., et al., 2014. Potential for increased photosynthetic performance and crop productivity in response to climate change: role of CBFs and gibberellic acid. Front. Chem. 2, 18.

Igarashi, Y., Yoshiba, Y., Sanada, Y., Yamaguchi-Shinozaki, K., Wada, K., Shinozaki, K., 1997. Characterization of the gene for $\Delta$ 1-pyrroline-5-carboxylate synthetase and correlation between the expression of the gene and salt tolerance in Oryza sativa L. Plant Mol. Biol. 33 (5), 857-865. 
Igarashi, Y., Yoshiba, Y., Takeshita, T., Nomura, S., Otomo, J., Yamaguchi-Shinozaki, K., et al., 2000. Molecular cloning and characterization of a cDNA encoding proline transporter in rice. Plant Cell Physiol. 41 (6), 750-756.

Imlay, J.A., Linn, S., 1988. DNA damage and oxygen radical toxicity. Science 240 (4857), 1302-1309.

Iqbal, N., Umar, S., Khan, N.A., Khan, M.I.R., 2014. A new perspective of phytohormones in salinity tolerance: regulation of proline metabolism. Environ. Exp. Bot. 100, 34-42.

Ishitani, M., Nakamura, T., Han, S.Y., Takabe, T., 1995. Expression of the betaine aldehyde dehydrogenase gene in barley in response to osmotic stress and abscisic acid. Plant Mol. Biol. 27 (2), 307-315.

Jagendorf, A.T., Takabe, T., 2001. Inducers of glycinebetaine synthesis in barley. Plant Physiol. 127 (4), 1827-1835.

Jiménez-Arias, D., Borges, A.A., Luis, J.C., Valdés, F., Sandalio, L.M., Pérez, J.A., 2015. Priming effect of menadione sodium bisulphite against salinity stress in Arabidopsis involves epigenetic changes in genes controlling proline metabolism. Environ. Exp. Bot. 120, $23-30$.

Kanade, M.B., 2008. Effect of foliar application of salicylic acid on polyphenol, proline and carbohydrates content in wheat and sorghum. Adv. Plant Sci. 21 (1), 321-322.

Kaul, S., Sharma, S.S., Mehta, I.K., 2008. Free radical scavenging potential of L-proline: evidence from in vitro assays. Amino Acids 34 (2), 315-320.

Kaushal, N., Gupta, K., Bhandhari, K., Kumar, S., Thakur, P., Nayyar, H., 2011. Proline induces heat tolerance in chickpea (Cicer arietinum L.) plants by protecting vital enzymes of carbon and antioxidative metabolism. Physiol. Mol. Biol. Plants 17 (3), 203-213.

Ke, X., Cheng, Z., Ma, W., Gong, M., 2014. Effects of nitric oxide on smoregulation of tobacco cells under salt stress. Acta Bot. Boreal Occident. Sin. 34, 1596-1607.

Khan, M.S., Yu, X., Kikuchi, A., Asahina, M., Watanabe, K.N., 2009. Genetic engineering of glycine betaine biosynthesis to enhance abiotic stress tolerance in plants. Plant Biotechnol. 26 (1), 125-134.

Khan, M.I.R., Khan, N.A., 2014. Ethylene reverses photosynthetic inhibition by nickel and zinc in mustard through changes in PS II activity, photosynthetic-nitrogen use efficiency and antioxidant metabolism. Protoplasma 251, 1007-1019.

Khan, M.I.R., Khan, N., 2017. Reactive Oxygen Species and Antioxidant System in Plants: Role and Regulation Under Abiotic Stress. Springer Nature, New York978-981-10-5254-5.

Khan, M.I.R., Asgher, M., Khan, N.A., 2014. Alleviation of saltinduced photosynthesis and growth inhibition by salicylic acid involves glycinebetaine and ethylene in mungbean (Vigna radiata L.). Plant. Physiol. Biochem. 80, 67-74.

Khan, M.I.R., Fatma, M., Per, T.S., Anjum, N.A., Khan, N.A., 2015. Salicylic acid-induced abiotic stress tolerance and underlying mechanisms in plants. Front. Plant Sci. 6, 462.

Kishor, P.B.K., Hong, Z., Miao, G.H., Hu, C.A.A., Verma, D.P.S., 1995. Overexpression of [delta]-pyrroline-5-carboxylate synthetase increases proline production and confers osmotolerance in transgenic plants. Plant Physiol. 108 (4), 1387-1394.

Kiyosue, T., Yoshiba, Y., Yamaguchi-Shinozaki, K., Shinozaki, K., 1996. A nuclear gene encoding mitochondrial proline dehydrogenase, an enzyme involved in proline metabolism, is upregulated by proline but downregulated by dehydration in Arabidopsis. Plant Cell 8 (8), 1323-1335.

Koch, K., 2004. Sucrose metabolism: regulatory mechanisms and pivotal roles in sugar sensing and plant development. Curr. Opin. Plant. Biol. 7 (3), 235-246.

Koch, K.E., Nolte, K.D., Duke, E.R., McCarty, D.R., Avigne, W.T., 1992. Sugar levels modulate differential expression of maize sucrose synthase genes. Plant Cell 4 (1), 59-69.
Kumar, N., Pal, M., Srivastava, G.C., 2009. Proline metabolism in senescing rose petals (Rosa hybrida L. 'First Red'). J. Hort. Sci. Biotechnol. 84 (1), 536-540.

Kumar, N., Pal, M., Singh, A., SaiRam, R.K., Srivastava, G.C., 2010. Exogenous proline alleviates oxidative stress and increase vase life in rose (Rosa hybrida L.'Grand Gala'). Sci. Hortic. (Amsterdam) 127 (1), 79-85.

Kumar, R., Zhao, S., Vetting, M.W., Wood, B.M., Sakai, A., Cho, K., et al., 2014. Prediction and biochemical demonstration of a catabolic pathway for the osmoprotectant proline betaine. mBio 5 (1), e00933-13.

Kurepin, L.V., Dahal, K.P., Savitch, L.V., Singh, J., Bode, R., Ivanov, A.G., et al., 2013. Role of CBFs as integrators of chloroplast redox, phytochrome and plant hormone signaling during cold acclimation. Int. J. Mol. Sci. 14 (6), 12729-12763.

Kurepin, L.V., Ivanov, A.G., Zaman, M., Pharis, R.P., Allakhverdiev, S.I., Hurry, V., et al., 2015. Stress-related hormones and glycinebetaine interplay in protection of photosynthesis under abiotic stress conditions. Photosynth. Res. 126 (2-3), 221-235.

Leprince, A.S., Magalhaes, N., De Vos, D., Bordenave, M., Crilat, E., Clément, G., et al., 2015. Involvement of phosphatidylinositol 3kinase in the regulation of proline catabolism in Arabidopsis thaliana. Front. Plant Sci. 5, 772.

Liang, X., Zhang, L., Natarajan, S.K., Becker, D.F., 2013. Proline mechanisms of stress survival. Antioxid. Redox. Signal. 19 (9), 998-1011.

Liu, J., Hu, H., Wang, X., Li, B., 2010. Effect of nitric oxide on proline accumulation in ryegrass seedlings subjected to salt stress. Acta Agrestia Sinica 18 (6), 786-791.

Liu, Y., Borchert, G.L., Surazynski, A., Hu, C.A., Phang, J.M., 2006. Proline oxidase activates both intrinsic and extrinsic pathways for apoptosis: the role of ROS/superoxides, NFAT and MEK/ERK signaling. Oncogene 25 (41), 5640.

Livingston, D.P., Tallury, S.P., Premkumar, R., Owens, S.A., Olien, C. R., 2005. Changes in the histology of cold-hardened oat crowns during recovery from freezing. Crop Sci. 45 (4), 1545-1558.

Livingston, D.P., Premakumar, R., Tallury, S.P., 2006. Carbohydrate partitioning between upper and lower regions of the crown in oat and rye during cold acclimation and freezing. Cryobiology 52 (2), 200-208.

Livingston, D.P., Hincha, D.K., Heyer, A.G., 2009. Fructan and its relationship to abiotic stress tolerance in plants. Cell. Mol. Life Sci. 66 (13), 2007-2023.

Llorca, C.M., Potschin, M., Zentgraf, U., 2014. bZIPs and WRKYs: two large transcription factor families executing two different functional strategies. Front. Plant Sci. 5, 169.

Lokhande, V.H., Suprasanna, P., 2012. Prospects of halophytes in understanding and managing abiotic stress tolerance. In: Parvaiz, A., Prasad, M.N.V. (Eds.), Environmental Adaptations to Changing Climate: Metabolism, Productivity and Sustainability. Springer, New York, pp. 29-56.

Lopez-Carrion, A.I., Castellano, R., Rosales, M.A., Ruiz, J.M., Romero, L., 2008. Role of nitric oxide under saline stress: implications on proline metabolism. Biol. Plant. 52 (3), 587.

Luo, Z., Li, D., Du, R., Mou, W., 2015. Hydrogen sulfide alleviates chilling injury of banana fruit by enhanced antioxidant system and proline content. Sci. Hortic. (Amsterdam) 183, 144-151.

Ma, Y., Szostkiewicz, I., Korte, A., Moes, D., Yang, Y., Christmann, A., et al., 2009. Regulators of PP2C phosphatase activity function as abscisic acid sensors. Science 324 (5930), 1064-1068.

Matiolli, C.C., Tomaz, J.P., Duarte, G.T., Prado, F.M., Del Bem, L.E. V., Silveira, A.B., et al., 2011. The Arabidopsis bZIP gene AtbZIP63 is a sensitive integrator of transient abscisic acid and glucose signals. Plant Physiol. 157 (2), 692-705. 
Matysik, J., Alia, Bhalu, B., Mohanty, P., 2002. Molecular mechanisms of quenching of reactive oxygen species by proline under stress in plants. Curr. Sci. 525-532.

Mehta, S.K., Gaur, J.P., 1999. Heavy-metal-induced proline accumulation and its role in ameliorating metal toxicity in Chlorella vulgaris. New Phytol. 143 (2), 253-259.

Miller, G., Honig, A., Stein, H., Suzuki, N., Mittler, R., Zilberstein, A., 2009. Unraveling $\Delta 1$-pyrroline-5-carboxylate-proline cycle in plants by uncoupled expression of proline oxidation enzymes. J. Biol. Chem. 284 (39), 26482-26492.

Misra, N., Saxena, P., 2009. Effect of salicylic acid on proline metabolism in lentil grown under salinity stress. Plant Sci. 177 (3), 181-189.

Mohapatra, S.S., Poole, R.J., Dhindsa, R.S., 1988. Abscisic acidregulated gene expression in relation to freezing tolerance in Alfalfa. Plant Physiol. 87 (2), 468-473.

Molinari, H.B.C., Marur, C.J., Daros, E., De Campos, M.K.F., De Carvalho, J.F.R.P., Pereira, L.F.P., et al., 2007. Evaluation of the stress-inducible production of proline in transgenic sugarcane (Saccharum spp.): osmotic adjustment, chlorophyll fluorescence and oxidative stress. Physiol. Plant. 130 (2), 218-229.

Morsy, M.R., Jouve, L., Hausman, J.F., Hoffmann, L., Stewart, J.M., 2007. Alteration of oxidative and carbohydrate metabolism under abiotic stress in two rice (Oryza sativa L.) genotypes contrasting in chilling tolerance. J. Plant. Physiol. 164 (2), 157-167.

Müller, J., Wiemken, A., Aeschbacher, R., 1999. Trehalose metabolism in sugar sensing and plant development. Plant Sci. 147 (1), 37-47.

Mundy, J., Chua, N.H., 1988. Abscisic acid and water-stress induce the expression of a novel rice gene. EMBO J. 7 (8), 2279-2286.

Murahama, M., Yoshida, T., Hayashi, F., Ichino, T., Sanada, Y., Wada, K., 2001. Purification and characterization of 81 -pyrroline5 -carboxylate reductase isoenzymes, indicating differential distribution in spinach (Spinacia oleracea L.) leaves. Plant Cell Physiol. 42 (7), 742-750.

Nayyar, H., Walia, D.P., 2004. Genotypic variation in wheat in response to water stress and abscisic acid-induced accumulation of osmolytes in developing grains. J Agron Crop Sci 190 (1), 39-45.

Neill, S., Barros, R., Bright, J., Desikan, R., Hancock, J., Harrison, J., et al., 2008. Nitric oxide, stomatal closure, and abiotic stress. J. Exp. Bot. 59 (2), 165-176.

Okuma, E., Murakami, Y., Shimoishi, Y., Tada, M., Murata, Y., 2004. Effects of exogenous application of proline and betaine on the growth of tobacco cultured cells under saline conditions. Soil Sci. Plant Nutr. 50 (8), 1301-1305.

Ozden, M., Demirel, U., Kahraman, A., 2009. Effects of proline on antioxidant system in leaves of grapevine (Vitis vinifera L.) exposed to oxidative stress by $\mathrm{H}_{2} \mathrm{O}_{2}$. Sci. Hortic. (Amsterdam) 119 (2), 163-168.

Papageorgiou, G.C., Murata, N., 1995. The unusually strong stabilizing effects of glycine betaine on the structure and function of the oxygen-evolving photosystem II complex. Photosynth. Res. 44 (3), 243-252.

Park, S.Y., Fung, P., Nishimura, N., Jensen, D.R., Fujii, H., Zhao, Y., et al., 2009. Abscisic acid inhibits PP2Cs via the PYR/PYL family of ABA-binding START proteins. Science (New York, NY) 324 (5930), 1068-1071.

Parre, E., Ghars, M.A., Leprince, A.S., Thiery, L., Lefebvre, D., Bordenave, M., et al., 2007. Calcium signaling via phospholipase $\mathrm{C}$ is essential for proline accumulation upon ionic but not nonionic hyperosmotic stresses in Arabidopsis. Plant Physiol. 144 (1), 503-512.

Peng, Z., Lu, Q., Verma, D.P.S., 1996. Reciprocal regulation of $\Delta^{1}$ pyrroline-5-carboxylate synthetase and proline dehydrogenase genes controls proline levels during and after osmotic stress in plants. Mol. Gen. Genet. 253 (3), 334-341.
Per, T.S., Khan, N.A., Reddy, P.S., Masood, A., Hasanuzzaman, M., Khan, M.I.R., et al., 2017. Approaches in modulating proline metabolism in plants for salt and drought stress tolerance: phytohormones, mineral nutrients and transgenics. Plant. Physiol. Biochem. 115, 126-140.

Per, T.S., Khan, M.I.R., Anjum, N.A., Masood, A., Hussain, S.J., Khan, N.A., 2018. Jasmonates in plants under abiotic stresses: crosstalk with other phytohormones matters. Environ. Exp. Bot. $145,104-120$.

Posmyk, M.M., Janas, K.M., 2007. Effects of seed hydropriming in presence of exogenous proline on chilling injury limitation in Vigna radiata L. seedlings. Acta Physiol. Plant. 29 (6), 509-517.

Rasheed, R., Wahid, A., Farooq, M., Hussain, I., Basra, S.M., 2011. Role of proline and glycinebetaine pretreatments in improving heat tolerance of sprouting sugarcane (Saccharum sp.) buds. Plant Growth Regul. 65 (1), 35-45.

Reddy, P.S., Jogeswar, G., Rasineni, G.K., Maheswari, M., Reddy, A. R., Varshney, R.K., et al., 2015. Proline over-accumulation alleviates salt stress and protects photosynthetic and antioxidant enzyme activities in transgenic sorghum [Sorghum bicolor (L.) Moench]. Plant. Physiol. Biochem. 94, 104-113.

Reiser, V., Raitt, D.C., Saito, H., 2003. Yeast osmosensor Sln1 and plant cytokinin receptor Cre1 respond to changes in turgor pressure. J. Cell. Biol. 161 (6), 1035-1040.

Rook, F., Gerrits, N., Kortstee, A., Van Kampen, M., Borrias, M., Weisbeek, P., et al., 1998. Sucrose-specific signalling represses translation of the Arabidopsis ATB2 bZIP transcription factor gene. Plant J. 15 (2), 253-263.

Rosa, M., Hilal, M., Gonzalez, J.A., Prado, F.E., 2009b. Lowtemperature effect on enzyme activities involved in sucrose-starch partitioning in salt-stressed and salt-acclimated cotyledons of quinoa (Chenopodium quinoa Willd.) seedlings. Plant. Physiol. Biochem. 47 (4), 300-307.

Rosa, M., Prado, C., Podazza, G., Interdonato, R., González, J.A., Hilal, M., et al., 2009a. Soluble sugars: metabolism, sensing and abiotic stress: a complex network in the life of plants. Plant Signal. Behav. 4 (5), 388-393.

Roy, D., Basu, N., Bhunia, A., Banerjee, S.K., 1993. Counteraction of exogenous L-proline with $\mathrm{NaCl}$ in salt-sensitive cultivar of rice. Biol. Plant. 35 (1), 69.

Sah, S.K., Reddy, K.R., Li, J., 2016. Abscisic acid and abiotic stress tolerance in crop plants. Front. Plant Sci. 7, 571.

Saito, H., Tatebayashi, K., 2004. Regulation of the osmoregulatory HOG MAPK cascade in yeast. J. Biochem. 136 (3), 267-272.

Sakamoto, A., Murata, N., 2002. The role of glycine betaine in the protection of plants from stress: clues from transgenic plants. Plant Cell Environ. 25 (2), 163-171.

Saradhi, P.P., AliaArora, S., Prasad, K.V.S.K., 1995. Proline accumulates in plants exposed to UV radiation and protects them against UV-induced peroxidation. Biochem. Biophys. Res. Commun. 209 (1), $1-5$.

Sarvesh, A., Anuradha, M., Pulliah, T., Reddy, T.P., Kavi Kishor, P. B., 1996. Salt stress and antioxidant response in high and low proline producing cultivars of niger, Guizotia abyssinica (Lf) Cass. Indian J. Exp. Biol. 34 (3), 252-256.

Satoh, R., Fujita, Y., Nakashima, K., Shinozaki, K., YamaguchiShinozaki, K., 2004. A novel subgroup of bZIP proteins functions as transcriptional activators in hypoosmolarity-responsive expression of the ProDH gene in Arabidopsis. Plant Cell Physiol. 45 (3), 309-317.

Satoh, R., Nakashima, K., Seki, M., Shinozaki, K., YamaguchiShinozaki, K., 2002. ACTCAT, a novel cis-acting element for proline-and hypoosmolarity-responsive expression of the ProDH gene encoding proline dehydrogenase in Arabidopsis. Plant Physiol. 130 (2), 709-719. 
Savouré, A., Jaoua, S., Hua, X.J., Ardiles, W., Van Montagu, M., Verbruggen, N., 1995. Isolation, characterization, and chromosomal location of a gene encoding the $\Delta 1$-pyrroline-5-carboxylate synthetase in Arabidopsis thaliana. FEBS Lett. 372 (1), 13-19.

Schat, H., Sharma, S.S., Vooijs, R., 1997. Heavy metal-induced accumulation of free proline in a metal-tolerant and a nontolerant ecotype of Silene vulgaris. Physiol. Plant. 101 (3), 477-482.

Schobert, B., 1977. Is there an osmotic regulatory mechanism in algae and higher plants? J. Theor. Biol. 68 (1), 17-26.

Schwartz, S.H., Zeevaart, J.A.D., 2010. Abscisic acid biosynthesis and metabolism. In: Davies, P.J. (Ed.), Plant Hormones: Biosynthesis, Signal Transduction and Action, third (revised) ed. Springer, Dordrecht, pp. 137-155.

Seiler, C., Harshavardhan, V.T., Reddy, P.S., Hensel, G., Kumlehn, J., Eschen-Lippold, L., et al., 2014. Abscisic acid flux alterations result in differential abscisic acid signaling responses and impact assimilation efficiency in barley under terminal drought stress. Plant Physiol. 164 (4), 1677-1696.

Shabala, S., Shabala, L., Van Volkenburgh, E., 2003. Effect of calcium on root development and root ion fluxes in salinised barley seedlings. Funct. Plant Biol. 30 (5), 507-514.

Sharma, S., Villamor, J.G., Verslues, P.E., 2011. Essential role of tissue-specific proline synthesis and catabolism in growth and redox balance at low water potential. Plant Physiol. 157 (1), 292-304.

Sharma, S.S., Dietz, K.J., 2006. The significance of amino acids and amino acid-derived molecules in plant responses and adaptation to heavy metal stress. J. Exp. Bot. 57 (4), 711-726.

Sharma, S.S., Schat, H., Vooijs, R., 1998. In vitro alleviation of heavy metal-induced enzyme inhibition by proline. Phytochemistry 49 (6), 1531-1535.

Shen, B., Jensen, R.G., Bohnert, H.J., 1997. Mannitol protects against oxidation by hydroxyl radicals. Plant Physiol. 115 (2), 527-532.

Shen, B., Hohmann, S., Jensen, R.G., Bohnert, H.J., 1999. Roles of sugar alcohols in osmotic stress adaptation. Replacement of glycerol by mannitol and sorbitol in yeast. Plant Physiol. 121 (1), $45-52$.

Shin, H., Oh, S., Kim, K., Kim, D., 2016. Proline accumulates in response to higher temperatures during dehardening in peach shoot tissues. Hort. J. 85 (1), 37-45.

Siripornadulsil, S., Traina, S., Verma, D.P.S., Sayre, R.T., 2002. Molecular mechanisms of proline-mediated tolerance to toxic heavy metals in transgenic microalgae. Plant Cell 14 (11), 2837-2847.

Smirnoff, N., Cumbes, Q.J., 1989. Hydroxyl radical scavenging activity of compatible solutes. Phytochemistry 28 (4), 1057-1060.

Smirnoff, N., Stewart, G.R., 1987. Nitrogen assimilation and zinc toxicity to zinc-tolerant and non-tolerant clones of Deschampsia cespitosa (L.) Beauv. New Phytol. 107 (4), 671-680.

Solomon, A., Beer, S., Waisel, Y., Jones, G.P., Paleg, L.G., 1994. Effects of $\mathrm{NaCl}$ on the carboxylating activity of Rubisco from Tamarix jordanis in the presence and absence of proline-related compatible solutes. Physiol. Plant. 90 (1), 198-204.

Storey, R., Jones, R.W., 1977. Quaternary ammonium compounds in plants in relation to salt resistance. Phytochemistry 16 (4), $447-453$.

Street, T.O., Bolen, D.W., Rose, G.D., 2006. A molecular mechanism for osmolyte-induced protein stability. Proc. Natl. Acad. Sci. 103 (38), 13997-14002.

Strizhov, N., Ábrahám, E., Ökrész, L., Blickling, S., Zilberstein, A., Schell, J., et al., 1997. Differential expression of two P5CS genes controlling proline accumulation during salt-stress requires ABA and is regulated by ABA1, ABI1 and AXR2 in Arabidopsis. Plant J. 12 (3), 557-569.

Su, M., Li, X.F., Ma, X.Y., Peng, X.J., Zhao, A.G., Cheng, L.Q., et al., 2011. Cloning two P5CS genes from bioenergy sorghum and their expression profiles under abiotic stresses and MeJA treatment. Plant Sci. 181 (6), 652-659.

Suzuki, N., Koussevitzky, S., Mittler, R.O.N., Miller, G.A.D., 2012. ROS and redox signalling in the response of plants to abiotic stress. Plant Cell Environ. 35 (2), 259-270.

Szabados, L., Savoure, A., 2010. Proline: a multifunctional amino acid. Trends. Plant. Sci. 15 (2), 89-97.

Tarczynski, M.C., Jensen, R.G., Bohnert, H.J., 1993. Stress protection of transgenic tobacco by production of the osmolyte mannitol. Science 259 (5094), 508-510.

Tester, M., Davenport, R., 2003. $\mathrm{Na}^{+}$tolerance and $\mathrm{Na}^{+}$transport in higher plants. Ann. Bot. (Lond.) 91 (5), 503-527.

Thevelein, J.M., 1984. Regulation of trehalose mobilization in fungi. Microbiol. Rev. 48 (1), 42.

Thiery, L., Leprince, A.S., Lefebvre, D., Ghars, M.A., Debarbieux, E., Savouré, A., 2004. Phospholipase D is a negative regulator of proline biosynthesis in Arabidopsis thaliana. J. Biol. Chem. 279 (15), 14812-14818.

Thornburg, R.W., 2007. Molecular biology of the Nicotiana floral nectary. In: Nicolson, S. (Ed.), Nectaries and Nectar. Springer-Verlag, Berlin, pp. 265-287.

Tian, B., Qiao, Z., Zhang, L., Li, H., Pei, Y., 2016. Hydrogen sulfide and proline cooperate to alleviate cadmium stress in foxtail millet seedlings. Plant. Physiol. Biochem. 109, 293-299.

Tripathi, B.N., Gaur, J.P., 2004. Relationship between copper-and zinc-induced oxidative stress and proline accumulation in Scenedesmus sp. Planta 219 (3), 397-404.

Uchida, A., Jagendorf, A.T., Hibino, T., Takabe, T., Takabe, T., 2002. Effects of hydrogen peroxide and nitric oxide on both salt and heat stress tolerance in rice. Plant Sci. 163 (3), 515-523.

Umezawa, T., Nakashima, K., Miyakawa, T., Kuromori, T., Tanokura, M., Shinozaki, K., et al., 2010. Molecular basis of the core regulatory network in ABA responses: sensing, signaling and transport. Plant Cell Physiol. 51 (11), 1821-1839.

Veerabagu, M., Kirchler, T., Elgass, K., Stadelhofer, B., Stahl, M., Harter, K., et al., 2014. The interaction of the Arabidopsis response regulator ARR18 with bZIP63 mediates the regulation of Proline dehydrogenase expression. Mol. Plant 7 (10), 1560-1577.

Verbruggen, N., Villarroel, R., Van Montagu, M., 1993. Osmoregulation of a pyrroline-5-carboxylate reductase gene in Arabidopsis thaliana. Plant Physiol. 103 (3), 771-781.

Vereyken, I.J., Chupin, V., Hoekstra, F.A., Smeekens, S.C., de Kruijff, B., 2003. The effect of fructan on membrane lipid organization and dynamics in the dry state. Biophys. J. 84 (6), 3759-3766.

Verslues, P.E., Bray, E.A., 2006. Role of abscisic acid (ABA) and Arabidopsis thaliana ABA-insensitive loci in low water potentialinduced $\mathrm{ABA}$ and proline accumulation. J. Exp. Bot. 57 (1), 201-212.

Vogel, G., Aeschbacher, R.A., Müller, J., Boller, T., Wiemken, A., 1998. Trehalose-6-phosphate phosphatases from Arabidopsis thaliana: identification by functional complementation of the yeast tps2 mutant. Plant J. 13 (5), 673-683.

Wang, H., Tang, X., Wang, H., Shao, H.B., 2015. Proline accumulation and metabolism-related genes expression profiles in Kosteletzkya virginica seedlings under salt stress. Front. Plant Sci. 6, 792.

Wang, N., Nobel, P.S., 1998. Phloem transport of fructans in the crassulacean acid metabolism species Agave deserti. Plant Physiol. 116 (2), 709-714.

Wei-Tao, L., Lin, B., Zhang, M., Hua, X.J., 2011. Proline accumulation is inhibitory to Arabidopsis seedlings during heat stress. Plant Physiol. 156 (4), 1921-1933.

Wu, J.T., Chang, S.C., Chen, K.S., 1995. Enhancement of intracellular proline level in cells of Anacystis nidulans (cyanobacteria) exposed to deleterious concentrations of copper. J. Phycol. 31 (3), $376-379$. 
Wu, J.T., Hsieh, M.T., Kow, L.C., 1998. Role of proline accumulation in response to toxic copper in Chlorella sp. (Chlorophyceae) cells. J. Phycol. 34 (1), 113-117.

Yamaguchi-Shinozaki, K., Shinozaki, K., 2006. Transcriptional regulatory networks in cellular responses and tolerance to dehydration and cold stresses. Annu. Rev. Plant. Biol. 57, 781-803.

Yang, S.L., Lan, S.S., Gong, M., 2009. Hydrogen peroxide-induced proline and metabolic pathway of its accumulation in maize seedlings. J. Plant. Physiol. 166 (15), 1694-1699.

Yang, X., Liang, Z., Lu, C., 2005. Genetic engineering of the biosynthesis of glycinebetaine enhances photosynthesis against high temperature stress in transgenic tobacco plants. Plant Physiol. 138 (4), 2299-2309.

Yang, X., Wen, X., Gong, H., Lu, Q., Yang, Z., Tang, Y., et al., 2007. Genetic engineering of the biosynthesis of glycinebetaine enhances thermotolerance of photosystem II in tobacco plants. Planta 225 (3), 719-733.

Yoshiba, Y., Kiyosue, T., Katagiri, T., Ueda, H., Mizoguchi, T., Yamaguchi-Shinozaki, K., et al., 1995. Correlation between the induction of a gene for $\Delta 1$-pyrroline-5-carboxylate synthetase and the accumulation of proline in Arabidopsis thaliana under osmotic stress. Plant J. 7 (5), 751-760.

You, J., Hu, H., Xiong, L., 2012. An ornithine $\delta$-aminotransferase gene OsOAT confers drought and oxidative stress tolerance in rice. Plant Sci. 197, 59-69.

Yuan, X., Wang, J., Xie, Y., Shen, W., 2009. Effect of carbon monoxide on salt tolerance and proline contents in root of wheat seedlings. Plant Physiol. Communicat. 45 (6), 567-570.

Zentella, R., Mascorro-Gallardo, J.O., Van Dijck, P., Folch-Mallol, J., Bonini, B., Van Vaeck, C., et al., 1999. A Selaginella lepidophylla trehalose-6-phosphate synthase complements growth and stresstolerance defects in a yeasttps1 mutant. Plant Physiol. 119 (4), 1473-1482.
Zhang, L., Becker, D., 2015. Connecting proline metabolism and signaling pathways in plant senescence. Front. Plant Sci. 6, 552.

Zhang, L., Gao, M., Hu, J., Zhang, X., Wang, K., Ashraf, M., 2012a. Modulation role of abscisic acid (ABA) on growth, water relations and glycinebetaine metabolism in two maize (Zea mays L.) cultivars under drought stress. Int. J. Mol. Sci. 13 (3), 3189-3202.

Zhang, L.P., Mehta, S.K., Liu, Z.P., Yang, Z.M., 2008. Copperinduced proline synthesis is associated with nitric oxide generation in Chlamydomonas reinhardtii. Plant Cell Physiol. 49 (3), $411-419$.

Zhang, C., Li, Y., Yuan, F., Hu, S., He, P., 2012b. Effects of hematin and carbon monoxide on the salinity stress responses of Cassia obtusifolia L. seeds and seedlings. Plant Soil 359 (1-2), 85-105.

Zhao, M.G., Chen, L., Zhang, L.L., Zhang, W.H., 2009. Nitric reductase-dependent nitric oxide production is involved in cold acclimation and freezing tolerance in Arabidopsis. Plant Physiol. 151 (2), 755-767.

Zhao, Y., Aspinall, D., Paleg, L.G., 1992. Protection of membrane integrity in Medicago sativa L. by glycinebetaine against the effects of freezing. J. Plant. Physiol. 140 (5), 541-543.

Zuther, E., Kwart, M., Willmitzer, L., Heyer, A.G., 2004. Expression of a yeast-derived invertase in companion cells results in longdistance transport of a trisaccharide in an apoplastic loader and influences sucrose transport. Planta 218 (5), 759-766.

\section{Further Reading}

Ruan, H.H., Shen, W.B., Xu, L.L., 2004. Nitric oxide involved in the abscisic acid induced proline accumulation in wheat seedling leaves under salt stress. Acta Botanica Sinica-English Edition 46 (11), 1307-1315. 